Original Research Paper

\title{
Glass Strength for Impact and Blast Loading
}

\author{
Matthias Förch and Frank Wellershoff \\ HafenCity University Hamburg, Professorship for Façade Systems and Building Envelopes, Hamburg, Germany
}

\author{
Article history \\ Received: $31-10-2020$ \\ Revised: 14-01-2021 \\ Accepted: 01-02-2021 \\ Corresponding Author: \\ Matthias Förch \\ Werner Sobek Hamburg, \\ Germany \\ Email: matthias.foerch@wernersobek.com
}

\begin{abstract}
Glass strength is highly influenced by strain rate. This material behaviour is well known in structural glass design and implemented in various standards. The strength of architectural glass is determined by component tests with a defined strain rate of $2 \mathrm{~N} /\left(\mathrm{mm}^{2} \mathrm{~s}\right)$, providing favourable terms for testing. As typical effects of actions on facades result in lower or higher strain rates, a strain rate factor must be implemented in structural design standards. Standard load cases as dead load, snow, climate and wind inducing low strain rates have been determined with sufficient accuracy by analytical models and extensive component testing. In difference, extensive experimental studies under higher strain rates are missing to cover accidental design situations as impact and blast. Here, only few test series are documented with a small number of test specimens, so that a statistical evaluation was not possible. Therefore, experimental tests are presented in this study, investigating the glass strength of annealed glass, heat strengthened glass and fully tempered glass under low-speed and high-speed conditions. To obtain statistical reliable experimental data, 160 glass specimens were tested, having stress rates in the relevant specimen center zones of $2 \mathrm{~N} /\left(\mathrm{mm}^{2} \mathrm{~s}\right)$ and $1,400 \mathrm{~N} /\left(\mathrm{mm}^{2} \mathrm{~s}\right)$. The surfaces of most specimens were pretreated with corundum to reduce the variation of glass surface bending strength. Further to verification of conducted tests by theoretical damage accumulation (risk integral method), load duration factors for impact and blast load design are proposed up to 1.12 for fully tempered glass and 1.4 for heat strengthened glass. On the basis of this results and other research, sufficient data are available to adapt load duration factors for impact and blast in structural design codes.
\end{abstract}

Keywords: Glass Strength, High-Strain-Rate, Impact, Blast Load, Bomb Blast Resistant Design

\section{Introduction}

The statistical analysis of terrorist attacks outside war zones unfortunately shows a long-term rising trend in events and casualty figures. While state security services try to prevent attacks, enhancement techniques with respect to structural planning establish. As a result, clients include bomb blast protection requirements increasingly in specifications to protect occupants.

Further to military research an urgent need for a glazing design procedure developed during the period of Irish terrorism in the 1980s and 1990s in the UK, which led, starting with a simplistic empirical procedure, to the development of the restricted UK Glazing Hazard Guide (1997) (Cormie et al., 2009). However, systematic civil research in the field of blast resistant glazing began after increasing terrorist incidents starting from the beginning of this century. Until recently, most terror attacks have been committed by the use of explosives that often lead to casualties and even fatalities. The human body is remarkably resilient to blast overpressure. The survival chance for lung damage of a $70 \mathrm{~kg}$ male in $3 \mathrm{~m}$ distance from a $27 \mathrm{~kg}$ TNT charge, generating an overpressure of $900 \mathrm{kN} / \mathrm{m}^{2}$ over $1 \mathrm{~ms}$, is approximately $99 \%$. The risk of eardrum rupture is greater than 50\% (Smith and Hetherington, 1994). In fact the majority of casualties produced by explosions result from the impact of fragments and debris striking the victim (Elsayed and Atkins, 2008). Main focus in this context ought to be on flying glass fragments (Weigel, 1980), from which a high hazard is posed. During the Oklahoma City Bombing in 1995, more than 80 percent of the 432 injured people were lacerated by glass splinters (Harpole, 1995). With reference to the 
example above, the kill probability of a $20 \mathrm{~g}$ glass splinter to abdomen and limbs with an impact velocity of $100 \mathrm{~m} / \mathrm{s}$ is $90 \%$ (Ahlers, 1969).

Hence accurate material parameters are crucial for engineers for a realistic prediction of glass panel behaviour subjected to blast load. With knowledge in distribution function of the material strength under the effective strain rate, the failure probability of individual glass panes can be determined and the percentage of broken panes in a façade respectively. However, in order to compensate brittle glass characteristics, laminated glass is used for bomb blast but also for (human) impact glass applications to achieve more ductility. The present research focusses on determination of glass strength under dynamic conditions that may appear under bomb blast or impact loading.

In general, strain rate dependency of glass strength is well known in structural glass design (Mould and Southwick, 1959; Marsh, 1964; Brown, 1969; Mencik, 1992; Lawn, 1993) and implemented in standards like DIN 18008-1 (2010-12), DIN 18008-4 (2013-07), E DIN EN 16612 (2013-06), ASTM E1300-16 (2016). Experimental research confirms an increase in bending strength as material behaviour (Schneider, 2001; Nie et al., 2010; Peroni et al., 2011; König, 2011; Kuntsche, 2015; Meyland et al., 2019). Schneider (2001) conducted glass strength tests under soft impact load for laminated annealed glass (10 specimens), fully tempered glass (3 specimens) and insulating glass (3 specimens), but due to the limited number of tests no statistically verified evidence was possible (Schneider, 2001). Nie et al. (2010) investigated the loading-rate and surface-condition effects on the flexural strength of borosilicate glass, concluding that the loading rate increases remarkably under all surface conditions. Peroni et al. (2011) assessed the dynamic behaviour of glass by splitting tensile test, documenting an increase in tensile strength at higher strain rate. König (2011) ran experimental tensile tests on annealed glass specimens under different strain rates with surface condition as delivered. Due to the limited number of tests and big scatter, a trend can be recognized (König, 2011). Kuntsche (2015) investigated monolithic glass plates under soft impact for annealed glass ( 5 specimens) and fully tempered glass ( 5 specimens). Due to the experimental results and theoretical considerations a rough estimation for factors $k_{\text {mod }}$ is presented (Kuntsche, 2015). Meyland et al. (2019) investigated 151 small circular specimens of soda-lime-silica glass at different loading rates with condition as delivered and predamaged, showing an increase in flexural strength of up to $85 \%$. Most of the mentioned experimental research do not allow for a verified assessment of glass strength due to the limited number of tests. However, a comparison of the presented test results with the above mentioned research is provided in Table 5 and Figs. 15 and 16.
The tests conducted at HafenCity University Hamburg (HCU) contribute to existing knowledge by proposing load duration factors $k_{\text {mod }}$ for impact and blast load design for annealed glass, heat strengthened glass and fully tempered glass. After a brief overview of load duration implementation in different standards, the experimental investigation is presented in detail. Here, the glass strength of annealed glass, heat strengthened glass and fully tempered glass is investigated under low-speed and high-speed conditions. To obtain statistical resilient experimental data, 160 glass specimens were tested, having stress rates in specimen center zones of 2 $\mathrm{N} /\left(\mathrm{mm}^{2} \mathrm{~s}\right)$ and $1,400 \mathrm{~N} /\left(\mathrm{mm}^{2} \mathrm{~s}\right)$. Further to verification of risk integral method for test results, it is shown that load duration factors can be determined for arbitrary stress histories on the basis of test results with consideration of residual surface compression. Assuming sinusoidal stress gradients applicable as approximation for impact and blast load response, factors $k_{\bmod }$ are determined for impact and blast load. Finally, factors $k_{\text {mod }}$ for impact and blast load design are proposed on the basis of Eurocode regulations with consideration of stress corrosion for annealed glass, heat strengthened glass and fully tempered glass and compared to current standard regulations and other research.

\section{Consideration of Load Duration in Standards}

\section{USA and ASTM Referenced Organizations}

In ASTM E1300-16 (2016), the load duration factors are implemented in the Glass Type Factors (GTF), which are applicable for load durations of 3 seconds or longer. For laminated glass subjected to blast loads, ASTM F2248-12 (2012) provides an equivalent 3-second duration static design load, depending on standoff distance and charge size in order to use the procedures of ASTM E1300-16 (2016). UFC 3-340-02 (2008) comprises design charts for peak blast pressure capacity of tempered glass, depending on peak pressure and duration of blast pressure (triangular impulse load). The charts are based on a maximum allowed principal tensile stress of 110 $\mathrm{N} / \mathrm{mm}^{2}$. This is "slightly higher than that commonly used in the design of one-minute wind loads" (UFC 3340-02, 2008).

\section{Europe}

In the European standard E DIN EN 16612 (2013-06), load duration is considered by load duration factor $k_{\text {mod }}$, referring to annealed glass only, implemented in the resistance value of bending strength $f_{g, d}$ :

$$
f_{g, d}=\frac{k_{\mathrm{mod}} k_{s p} f_{g, k}}{\gamma_{M, A}}
$$


where, $k_{s p}$ is the surface conditions constant, $\gamma_{M, A}$ is the partial safety factor of the material and $f_{g, k}$ is the characteristic bending strength, determined by coaxial double ring or four point bending test according to DIN EN 1288-3 (2000-09). In these tests the stress rate is 2 $\mathrm{N} /\left(\mathrm{mm}^{2} \mathrm{~s}\right)$. For glass with surface compression, Eq. (1) is complemented to:

$f_{g, d}=\frac{k_{\mathrm{mod}} k_{s p} f_{g, k}}{\gamma_{M, A}}+\frac{k_{V}\left(f_{b, k}-f_{g, k}\right)}{\gamma_{M, V}}$

where, $k_{V}$ is the strengthening factor, $f_{b, k}$ is the characteristic bending strength of glass with surface compression, determined by DIN EN 1288-3 (2000-09) and $\gamma_{M, V}$ is the partial safety factor for surface compression.

Explicit, load duration factors $k_{\text {mod }}$ are available for constant loads of 30 seconds or longer. For accidental design situations with very short duration longer than $20 \mathrm{~ms}$, e.g., blast loads, factors $k_{\text {mod }}$ can be determined by (E DIN EN 16612, 2013-06):

$k_{\mathrm{mod}}=0.663 t^{-\frac{1}{16}}$

where, $t$ is the load duration in hours. There exists no information with regard to the stress history caused by such accidental design situations with very short load.

\section{Germany}

In contrast to European definition, where factors $k_{\text {mod }}$ are referring to annealed glass only, the German standards DIN 18008-1 (2010-12) and DIN 18008-4 (2013-07) are referring to each different glass type. For short load duration, e.g., wind or barrier load, factors $k_{\text {mod }}$ for constant stress histories are provided in DIN 18008-1 (2010-12). For soft impact loads, factors $k_{\text {mod }}$ are provided in DIN 18008-4 (2013-07), while the bending strength $f_{d}$ is calculated as follows (DIN 18008-4, 2013-07, Eq.C.1):

$f_{d}=\frac{k_{\bmod } f_{k}}{\gamma_{M}}$

where, $f_{k}$ is the characteristic bending strength, determined by coaxial double ring or four point bending test (DIN EN 1288-3, 2000-09) and $\gamma_{M}$ is the partial factor, which is set to 1.0 for impact loads. Although not explicitly mentioned, sinusoidal stress history appears to be considered, see, for example, the verification charts for transient calculation (DIN 18008-4, 2013-07). In the investigations of Schneider (2001), constituting the basis of the actual German standard (Kuntsche, 2015), a duration of impact loads (soft impact) between 40 and $100 \mathrm{~ms}$ is described.

\section{Experimental Investigation}

Glass tests based on DIN EN 1288-3 (2000-09) were performed in the laboratory at HCU. Two stress rates $\dot{\sigma}\left(\varepsilon_{x}\right)$ in specimen center zone were investigated: (1) low-speed with $2 \mathrm{~N} /\left(\mathrm{mm}^{2} \mathrm{~s}\right)$ and (2) high-speed with 1,400 N/(mm² $)$.

Lateral stresses were not considered according to DIN EN 1288-3 (2000-09). Figure 1 shows the setup for all low-speed and high-speed tests. High-speed cameras were used for initial crack identification during high-speed tests. Initial crack identification for low-speed tests was done by analysis of fracture pattern after testing. All specimens of presented test series were prepared with one uniaxial strain gauge in center of tin side (tensile zone during test). Furthermore, a foil was applied to the gas side (compression zone during test) of all specimens to facilitate the initial crack identification after low-speed testing and to maximize the safety level with regard to glass splinters.

\section{Test Specimens}

The following soda lime silicate glass types originating from the same production batch are investigated: (1) Annealed glass (product name: Float 4 $\mathrm{mm}$ ), (2) Heat strengthened glass (product name: Sanco-Dur Teilvorgespannt $4 \mathrm{~mm}$ ) and (3) Fully tempered glass (product name: Sanco-Dur Float klar 4 $\mathrm{mm}$ ) with nominal dimensions $1,100 \times 360 \times 4 \mathrm{~mm}$ and fine grinded edge quality. All relevant parameters of the delivered glass specimens were measured: width (accuracy $1 \mathrm{~mm}$ ), height (accuracy $0.01 \mathrm{~mm}$ ) and residual surface compression measured on the tin side (precision: $\pm 2 \mathrm{~N} / \mathrm{mm}^{2}$ for stresses $<20 \mathrm{~N} / \mathrm{mm}^{2}$ otherwise $\pm 5 \%$ ).

\section{Corundum Treatment of Specimens}

In order to reduce the variation of bending strength and guide the initial crack in the mid area of specimen, most of the specimens were treated with corundum P16 with a drop height of $500 \mathrm{~mm}$. The glass edges were masked with tape during corundum treatment for protection, as edge bending strength was not object of investigation. The corundum treatment properties are presented in Fig. 2 and 3 . In order to avoid any influences with regard to crack healing effects, where flawed specimens show a strength increase in stress-free phase (Wiederhorn and Townsend, 1970; Haldimann et al., 2008; Schneider et al., 2016), the maximum time between corundum treatment and testing was limited to $30 \mathrm{~min}$. The extent of the corundum treatment at HafenCity University (HCU) was defined by iterative adjustment of drop height and opening width of the funnel in orientation to the surface treated glass series presented in Blank (1993), who defines the design point for resistance of annealed glass on the cumulative Weibull distribution function to $24.7 \mathrm{~N} / \mathrm{mm}^{2}$ with probabilistic 
considerations for RC2 for 50 years reference period. Güsgen (1998) and Sedlacek et al. (1999) use the work of Blank (1993) to define the partial factor $\gamma_{M}$ for annealed glass, representing the difference between surface as delivered and treated surface as:

$\gamma_{M}=\frac{f_{k}}{f_{d}}=\frac{45}{24.7} \approx 1.8$

\section{Testing Machine and Load Function}

The testing machine at HafenCity University (HCU) is capable of operating in low-speed and high-speed mode with a control frequency up to $10,000 \mathrm{~Hz}$ and $10 \mathrm{~m} / \mathrm{s}$ with high accuracy by using different sets of oil valves. For low-speed tests, the glass specimens were placed first onto the supporting steel cylinders, bearing dead stress condition (Fig. 1). Secondly, the test was run with the mentioned constant target piston speed, while the loading steel cylinders, attached to piston, started from free position, loading the glass specimen after a few seconds. The high-speed testing procedure was as follows: Firstly, placing the glass specimen onto the supporting steel cylinders. Secondly, setting up contact between loading steel cylinders, attached to piston and glass specimen in order to avoid impact load (Fig. 7b and 7d). Thirdly, start of high-speed test. The piston speed of testing machine for low-speed tests was defined with a constant value of 1.46 $\mathrm{mm} / \mathrm{s}$, which corresponds to a stress rate $\dot{\sigma}\left(\varepsilon_{x}\right)$ of 2 $\mathrm{N} /\left(\mathrm{mm}^{2} \mathrm{~s}\right)$ in center zone of specimen (height $\left.4 \mathrm{~mm}\right)$. This stress rate is defined in DIN EN 1288-3 (2000-09). On the basis of a FEA model for high-speed testing, a piston speed plateau of $1,000 \mathrm{~mm} / \mathrm{s}$ (Fig. 4) was defined, resulting in a stress rate $\dot{\sigma}\left(\varepsilon_{x}\right)$ of $1,400 \mathrm{~N} /\left(\mathrm{mm}^{2} \mathrm{~s}\right)$ in center zone of specimen (height $4 \mathrm{~mm}$ ). At this speed level, the surface strain rate is $2 \mathrm{E}-02 \mathrm{~s}^{-1}\left(2.9 \mathrm{E}-05 \mathrm{~s}^{-1}\right.$ for low-speed tests). This is appropriate for most glass pane analyses under impact and blast load, while the stress proportions of higher natural frequencies, which cause peaks in the stress gradients, are acceptable. Figure 4 shows the stress gradients $\sigma\left(\varepsilon_{x}\right)$ for fully tempered glass, based on Hooke's law, in center point of all corundum treated glass specimens during high-speed testing having a good level of alignment.

\section{Test Results}

In total, 160 specimens were tested in low-speed and high-speed condition (Table 1). All corundum treated specimens showed the initial crack in the mid area of specimens. In contrast, the two annealed glass series (20 specimens each) with surface condition as delivered predominantly showed initial cracks at glass edges (lowspeed 15 out of 20 and high-speed 17 out of 20), which should be kept in mind while evaluating Fig. 5. All specimens had initial cracks between loading cylinders attached to piston of testing machine (Fig. 1a). The ambient temperature during testing was between $20^{\circ} \mathrm{C}$ and $21^{\circ} \mathrm{C}$ and the ambient relative humidity was $40 \%$ for 6 test series, $45 \%$ for the low-speed, corundum treated heat strengthened glass series and $50 \%$ for the low-speed, surface as delivered annealed glass series. Basic assumption of the following assessment is the validity of Hooke's law for the investigated soda lime silicate glass with constant and strain-rate independent modulus of elasticity, that is applicable for "small short-term loading at room temperature" (Mencik, 1992). This assumption is supported by strain-rate tensile experiments on soda lime silica glass from König (2011) for the investigated strain rates $2.9 \mathrm{E}-05 \mathrm{~s}^{-1}$ for low-speed tests and $2 \mathrm{E}-02 \mathrm{~s}^{-1}$ for high-speed tests at HCU. A modulus of elasticity of $70,000 \mathrm{~N} / \mathrm{mm}^{2}$ is used (DIN EN 1288-3, 200009; DIN 18008-1, 2010-12; E DIN EN 16612, 2013-06; DIN EN 572-1, 2016-06). For statistical analysis a log-normal distribution implemented in DIN EN 1990 (2010-12) is considered, with plotting position formula according to Weibull. Results of all conducted low-speed and high-speed tests (20 specimens per series) are shown in Fig. 5 for bending strength $\sigma_{b B}$.

Table 1: Overview of conducted low-speed and high-speed glass tests at HafenCity University Hamburg

\begin{tabular}{lllll}
\hline $\begin{array}{l}\text { Glass type } \\
{[-]}\end{array}$ & $\begin{array}{l}\text { Surface condition } \\
{[-]}\end{array}$ & $\begin{array}{l}\text { No. of specimens } \\
{[-]}\end{array}$ & $\begin{array}{l}\text { Testing temp. } \\
{\left[{ }^{\circ} \mathrm{C}\right]}\end{array}$ & $\begin{array}{l}\text { Ambient relative humidity } \\
{[\%]}\end{array}$ \\
\hline $\begin{array}{l}\text { Low-speed }{ }^{\text {a) }} \\
\text { Annealed }\end{array}$ & As delivered & 20 & 20 & 50 \\
Annealed & Corundum treated & 20 & 20 & 40 \\
Heat strengthened & Corundum treated & 20 & 20 & 45 \\
Fully tempered & Corundum treated & 20 & 21 & 40 \\
High-speed & & & & 40 \\
Annealed & As delivered & 20 & 21 & 40 \\
Annealed & Corundum treated & 20 & 21 & 40 \\
Heat strengthened & Corundum treated & 20 & 21 & 40 \\
Fully tempered & Corundum treated & 20 & 21 &
\end{tabular}

a Stress rate in center zone of specimen $\dot{\sigma}\left(\varepsilon_{x}\right)=2 \mathrm{~N} /\left(\mathrm{mm}^{2} \mathrm{~s}\right)$ and $1,400 \mathrm{~N} /\left(\mathrm{mm}^{2} \mathrm{~s}\right)$ 


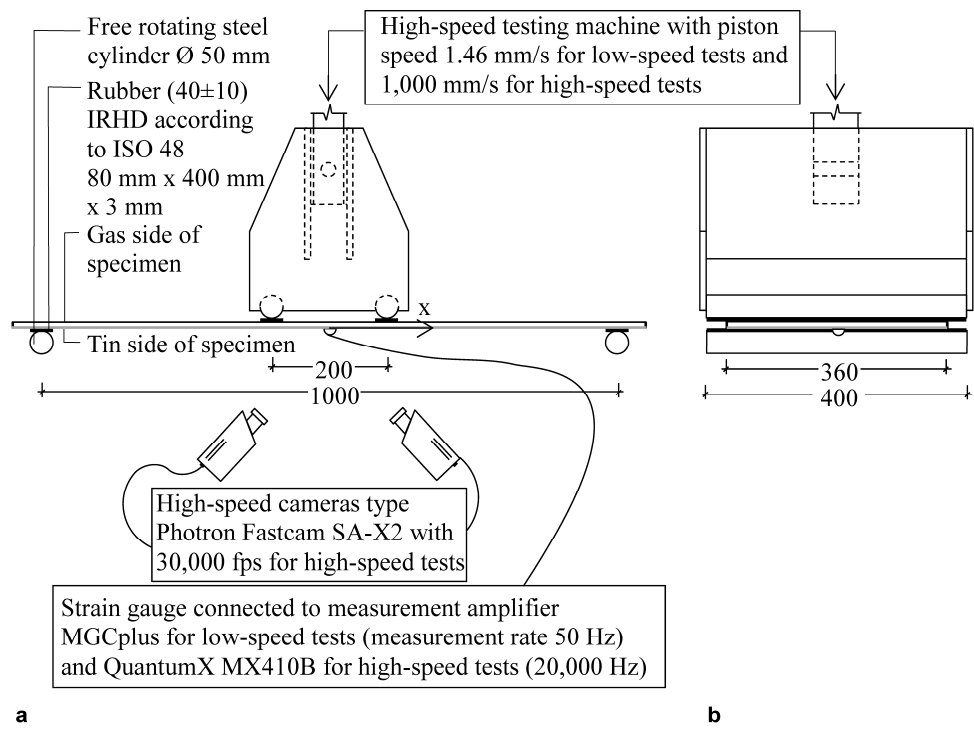

Fig. 1: Setup for four point bending tests based on DIN EN 1288-3 (2000-09). (a) Front view. (b) Side view
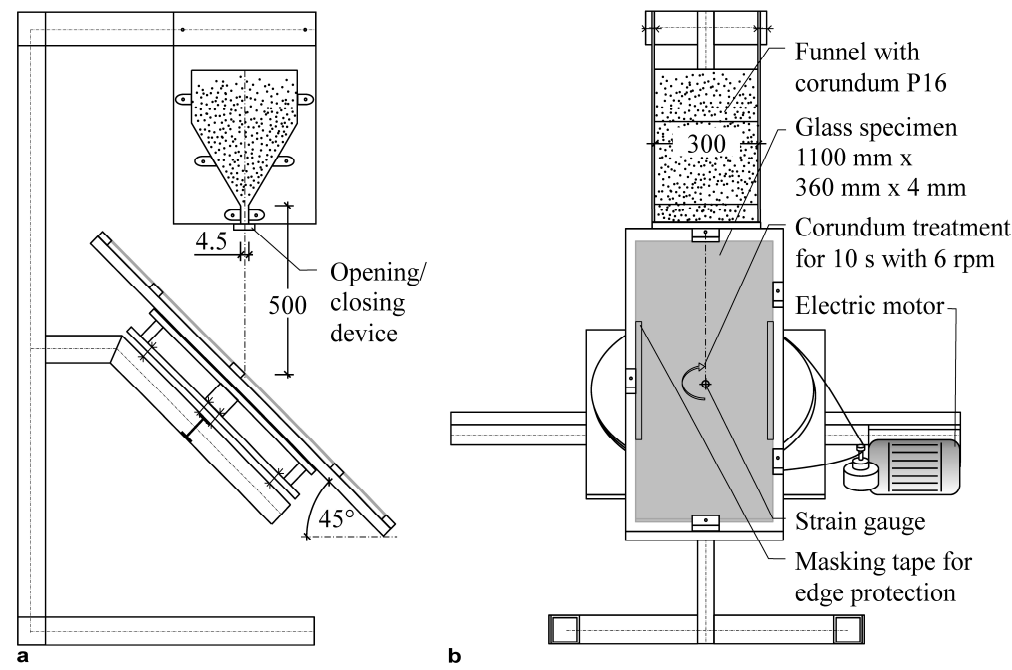

Fig. 2: Corundum treatment stand at HafenCity University Hamburg. (a) Side view. (b) Front view

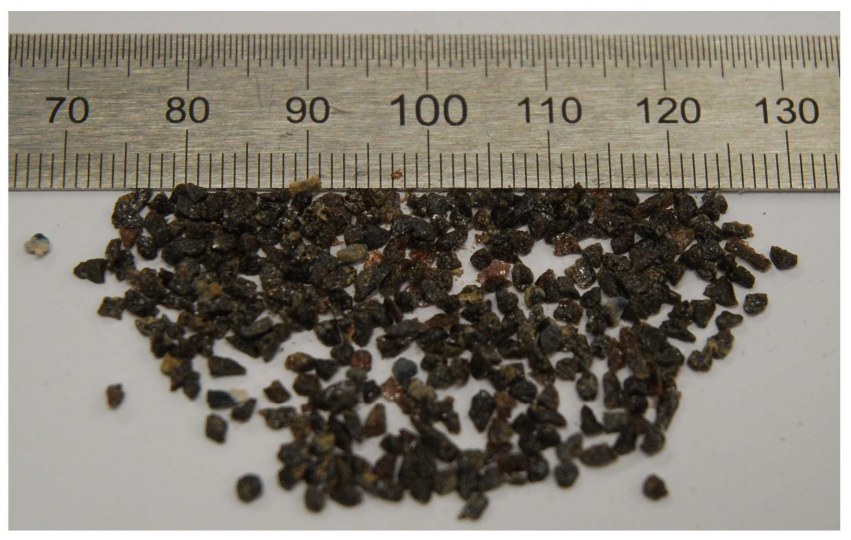

Fig. 3: Corundum P16 used for corundum treatment 


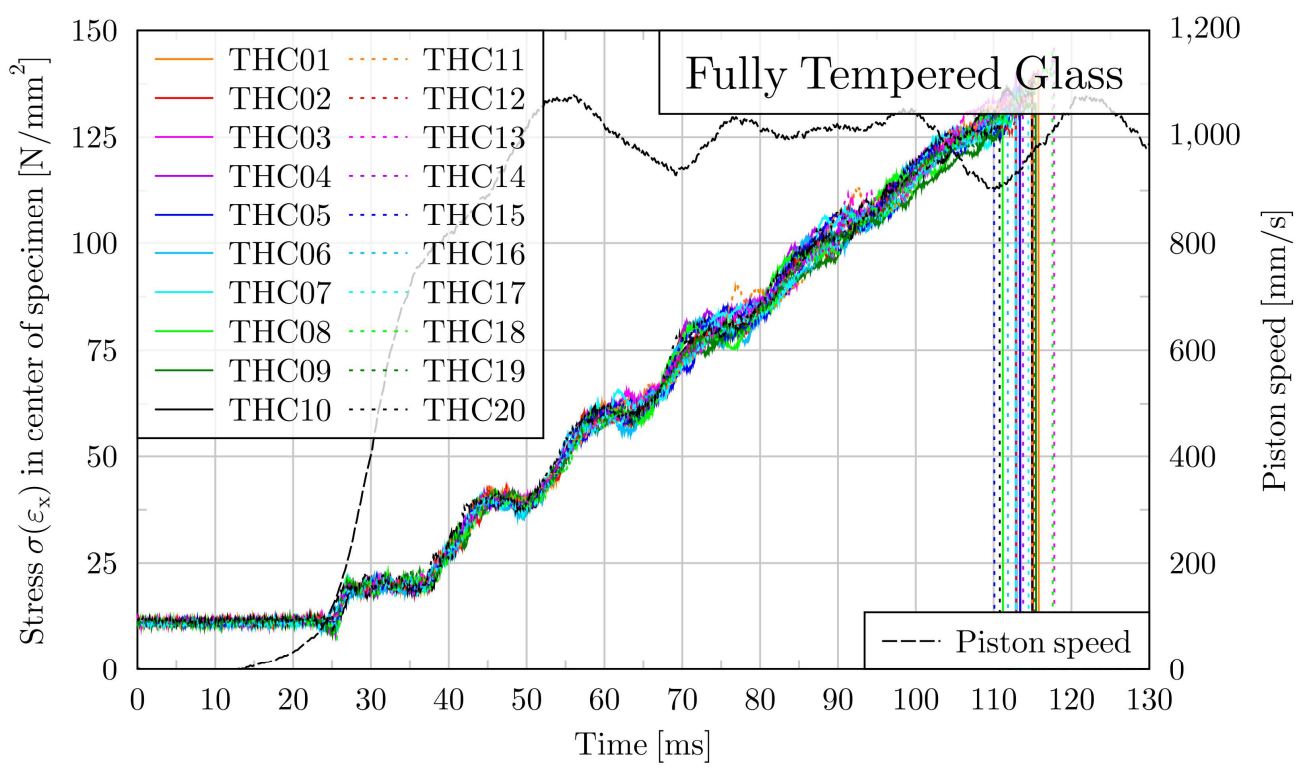

Fig. 4: Stress gradients $\sigma\left(\varepsilon_{x}\right)$ in center point of fully tempered $(\mathrm{T})$ specimens during high-speed $(\mathrm{H})$ tests with corundum treatment $(\mathrm{C})$. Stresses are determined from uniaxial $\varepsilon_{x}$ strains with constant modulus of elasticity of $70,000 \mathrm{~N} / \mathrm{mm}^{2}$

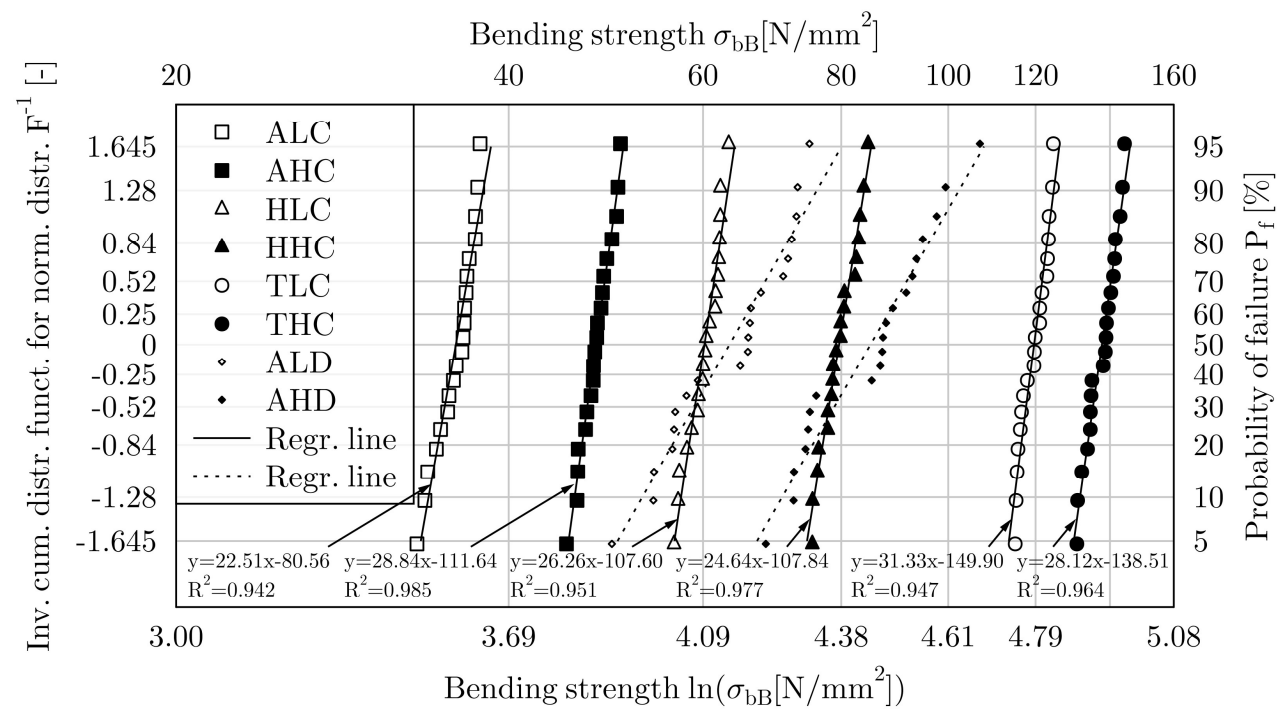

Fig. 5: Log-normal distribution of bending strength $\sigma_{b B}$ of annealed $(A)$, heat strengthened $(H)$ and fully tempered $(\mathrm{T})$ glass in low-speed (L) or high-speed (H) test with corundum treatment (C) or as delivered (D)

\section{Evaluation Methodology of Tests}

Subsequently, the German definition of factors $k_{m o d}$ is used (Eq. 4). Before determining factors $k_{\text {mod }}$ for sinusoidal stress gradients (Fig. 6), which can be used for impact and blast load design, the applicability of risk integral method for the present test series is examined in the following Section. The verification is done by comparison of two different methods for determination of load duration factors $k_{\text {mod }}$ (1)
Mean value method acc. to subsequent Section and (2) Risk integral method afterwards. After verification of the risk integral method by tests in subsequent Section, it is possible to convert the triangular stress gradient into any arbitrary stress history. For impact and blast loading a sinusoidal stress gradient is applied as this gradient is most appropriate for glass panel response. An overview of the applied evaluation methodology is given in Fig. 6. 


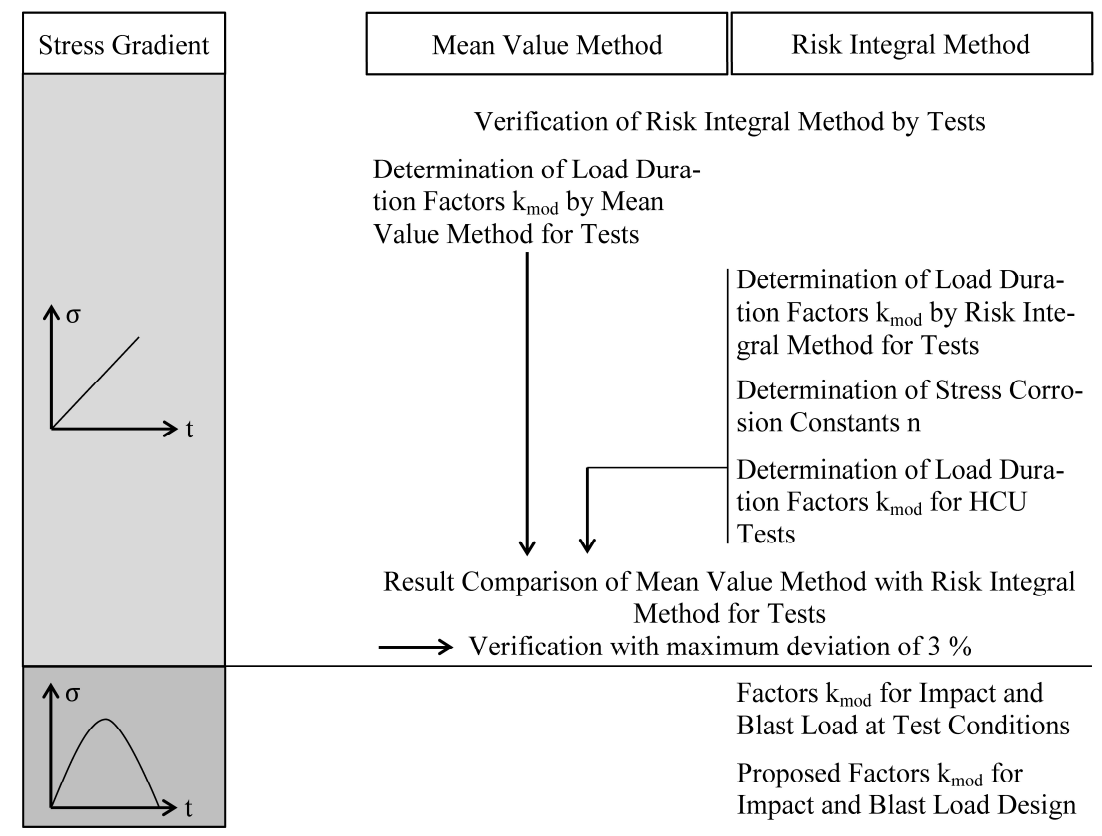

Fig. 6: Overview of the methodology for verification of risk integral method by tests and determination of factors $k_{\bmod }$ for impact and blast load design

\section{Verification of Risk Integral Method by Tests}

\section{Determination of Load Duration Factors $k_{\text {mod }}$ by Mean Value Method for Tests}

Based on the mean values of log-normal distribution in Fig. 5, the factors $k_{m o d}$ can be determined by forming quotients of bending strength $\sigma_{b B}$ from high-speed to lowspeed values, as the low-speed tests are according to DIN EN 1288-3 (2000-09):

$$
k_{\bmod }=\frac{\sigma_{b B, H}}{\sigma_{b B, L}}
$$

While this method is quite convenient, it suffers from resulting factors $k_{\text {mod }}$, which are only valid for the conducted tests with triangular stress gradient. Table 2 summarizes the results for corundum treated glass specimens. Results from annealed glass specimens with surface condition as delivered are not considered in Table 2 because of strong edge effects and big scatter. However, 40 annealed glass specimens were tested with surface condition as delivered, predominantly showing initial cracks at glass edges (low-speed 15 out of 20 and high-speed 17 out of 20). Although the resulting factors $k_{\text {mod }}=1.25$ for mid area and $k_{\text {mod }}=1.35$ for edges are not statistically firm because of the small number of tests in combination with big variation for surface condition as delivered, it can be stated that the factors $k_{m o d}$ are in the same range as for annealed glass with corundum treatment.

\section{Determination of Load Duration Factors $k_{\text {mod }}$ by Risk Integral Method for Tests}

To characterize damage accumulation in glass for a specific stress history, the risk integral method is widely used, e.g., in Mencik (1992), Sedlacek et al. (1999), Siebert (2001) and Haldimann et al. (2008). The risk integral, sometimes referred to as Brown's integral, is a criterion for strength and lifetime determination in structural glass design. It states that an accumulated time-dependent inherent stress $\sigma_{i}$ acting on a specimen (without residual surface compression) until fracture time $t_{f}$ is constant (adapted from Brown, 1969):

$\int_{0}^{t_{f}} \sigma_{i}(t)^{n} d t=$ constant

Stress corrosion constant $n$ is dimensionless, determined from tests and usually considered to be constant. Beside stress history, which is directly implemented in Eq. (7), the integral depends on the following influences (Siebert, 2001; Haldimann et al., 2008): (1) Environmental conditions (humidity, temperature, ambient medium) and age, (2) Depth and geometry of surface flaws, (3) Chemical composition of the glass, (4) Size of loaded area and (5) Residual surface compression. 
Matthias Förch and Frank Wellershoff / International Journal of Structural Glass and Advanced Materials Research 2021, Volume 5: 115.133 DOI: $10.3844 /$ sgamrsp.2021.115.133

Table 2: Factors $k_{m o d}$ of corundum treated glass obtained by mean value of bending strength $\sigma_{b B}$

\begin{tabular}{|c|c|c|c|}
\hline $\begin{array}{l}\text { Glass type } \\
{[-]}\end{array}$ & $\begin{array}{l}\text { Stress rate in centerzone of } \\
\text { specimen } \dot{\sigma}(\varepsilon x)\left[\mathrm{N} /\left(\mathrm{mm}^{2} \mathrm{~s}\right)\right]\end{array}$ & $\begin{array}{l}\text { Mean value }{ }^{a)} \text { of bending } \\
\text { strength } \sigma_{b B}\left[\mathrm{~N} / \mathrm{mm}^{2}\right]\end{array}$ & $\begin{array}{l}\text { Load duration factor } \mathrm{k}_{\bmod } \\
{[-]}\end{array}$ \\
\hline Annealed & $\begin{array}{l}2 \\
1,400\end{array}$ & $\begin{array}{l}35.8 \\
48.0\end{array}$ & 1.34 \\
\hline Heat strengthened & $\begin{array}{l}2 \\
1,400\end{array}$ & $\begin{array}{l}60.2 \\
79.6\end{array}$ & 1.32 \\
\hline Fully tempered & $\begin{array}{l}2 \\
1,400\end{array}$ & $\begin{array}{l}119.6 \\
137.7\end{array}$ & 1.15 \\
\hline
\end{tabular}

a based on log-normal distribution

Table 3: Literature review of stress corrosion constant $n$ for annealed soda lime silicate glass

\begin{tabular}{|c|c|c|c|c|c|}
\hline $\begin{array}{l}\text { Reference } \\
{[-]}\end{array}$ & $\begin{array}{l}\text { Surface } \\
{[-]}\end{array}$ & $\begin{array}{l}\text { Relative humidity } \\
{[\%]}\end{array}$ & $\begin{array}{l}\text { Temp. } \\
{\left[{ }^{\circ} \mathrm{C}\right]}\end{array}$ & $\begin{array}{l}\text { Stress rate } \\
{\left[\mathrm{N} /\left(\mathrm{mm}^{2} \mathrm{~s}\right)\right]}\end{array}$ & $\begin{array}{l}\text { Stress corrosion } \\
\text { constant } n[-]\end{array}$ \\
\hline Wiederhorn (1967) & Introduced cracks & $\begin{array}{l}\text { Vacuum } \\
0.017 \\
10 \\
30 \\
100 \\
\text { Water }\end{array}$ & 25 & - & $\begin{array}{l}93.3^{\text {a) }} \\
27.2^{\text {a) }} \\
21.4^{\text {a) }} \\
22.6^{\text {a) }} \\
20.8^{\text {a) }} \\
17.4^{\text {a) }}\end{array}$ \\
\hline Richter (1974) & Introduced cracks & 50 & 24 & - & $18.1^{\mathrm{b})}$ \\
\hline Gehrke et al. (1987) & - & 50 & - & 5 E-05 - 1 E-02 & 18.1 \\
\hline Gehrke and Ullner (1988) & Introduced cracks & 50 & - & - & 18.1 \\
\hline Ullner and Höhne (1993) & Introduced cracks & 50 & - & $2 \mathrm{E}-05-3 \mathrm{E}+02$ & $19.7^{\mathrm{a})}$ \\
\hline Sglavo and Green (1995) & Introduced cracks & 45 & 20 & $10-100$ & 18.8 \\
\hline $\mathrm{HCU}^{\mathrm{c})}$ & Corundum treated & 40 & 20 & $2-1400$ & 17.9 \\
\hline
\end{tabular}

a Values derived from Schula (2015)

b Values derived from Kerkhof et al. (1981)

c According to annealed glass HCU test series with corundum treatment (ALC and AHC)

Considering all influences to be constant, the risk integral is a powerful tool to determine times until fracture $\left(t_{f}\right)$ for varying stress histories. With application of the risk integral method to the conducted tests, it is possible to determine factors $k_{\text {mod }}$, as all influences mentioned above are kept constant during testing. As a result, the following procedure is elaborated: (1) Determination of stress corrosion constants $n$ and (2) Determination of load duration factors $k_{\text {mod }}$ for HCU tests afterwards (Fig. 6).

\section{Determination of Stress Corrosion Constants $n$}

The stress corrosion constant $n$ can be determined from Low-speed (L) and High-speed $(\mathrm{H})$ tests according to Eq. (8):

$$
\int_{0}^{t_{f, L}} \sigma_{i, L}(t)^{n} d t=\int_{0}^{t_{f, H}} \sigma_{i, H}(t)^{n} d t
$$

The stresses $\sigma_{i, L}$ and $\sigma_{i, H}$ are strictly related to inherent stress $\sigma_{i}$ (without residual surface compression proportion due to annealing, tempering or chemical hardening), contributing to risk integral only. Therefore it has to be distinguished between inherent strength $\sigma_{i B}$ and bending strength $\sigma_{b B}$, connected to each other by residual surface stress $\sigma_{c}$ (negative sign when compression): $\sigma_{i B}=\sigma_{b B}+\sigma_{c}$

In order to examine the damage accumulation proportion of inherent stress $\sigma_{i}$, Fig. 7 illustrates typical simplified stress histories for the conducted tests for corundum treated annealed and fully tempered glass under low-speed and high-speed tests. Evaluation of Eq. (8) for the 120 performed corundum treated glass tests, based on mean values of integrals (log-normal distribution) and trapezoidal rule with integration interval 5 E-05 s (grey areas in Fig. 7), results in the following stress corrosion constants $n$ : (1) $n=17.9$ for annealed glass, (2) $n=7.4$ for heat strengthened glass and (3) $n=7.1$ for fully tempered glass.

A comparison with stress corrosion constants $n$ for annealed glass reported in the literature is shown in Table 3.

A comprehensive literature research of $n$ values can be found in Schula (2015). For heat strengthened glass and fully tempered glass no $n$ values have been found in literature. However, all $n$ values of the present study refer to surface stress condition as the strains were measured at the glass surface. Hence the stress corrosion constants $n$ for heat strengthened glass and fully tempered glass have lower values as the stress intensity at the tip of the crack differs due to surface compression. Figure 8 presents surface 
compression stress condition, bending stress condition and their superposition for all regarded glass types. Here the difference between surface stress condition and stress condition at tip of crack becomes obvious.
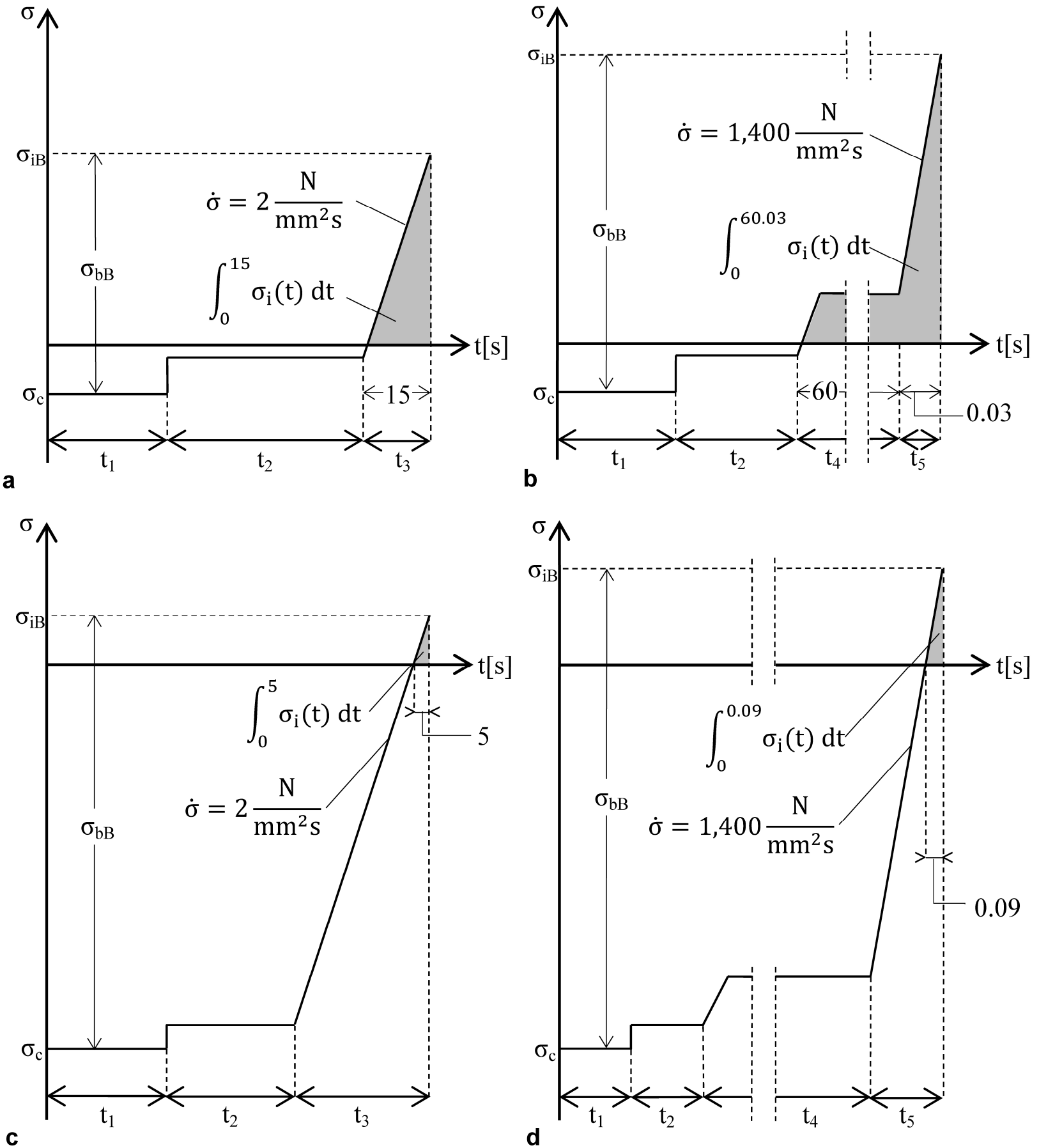

$\mathrm{t}_{1}$ : Without load; $\mathrm{t}_{2}$ : Dead stress condition; $\mathrm{t}_{3}$ : Low-speed; $\mathrm{t}_{4}$ : Contact of loading cylinders; $\mathrm{t}_{5}$ : High-speed

Fig. 7: Typical simplified stress histories for conducted tests. (a) Annealed glass in low-speed test. (b) Annealed glass in high-speed test. (c) Fully tempered glass in low-speed test. (d) Fully tempered glass in high-speed test 


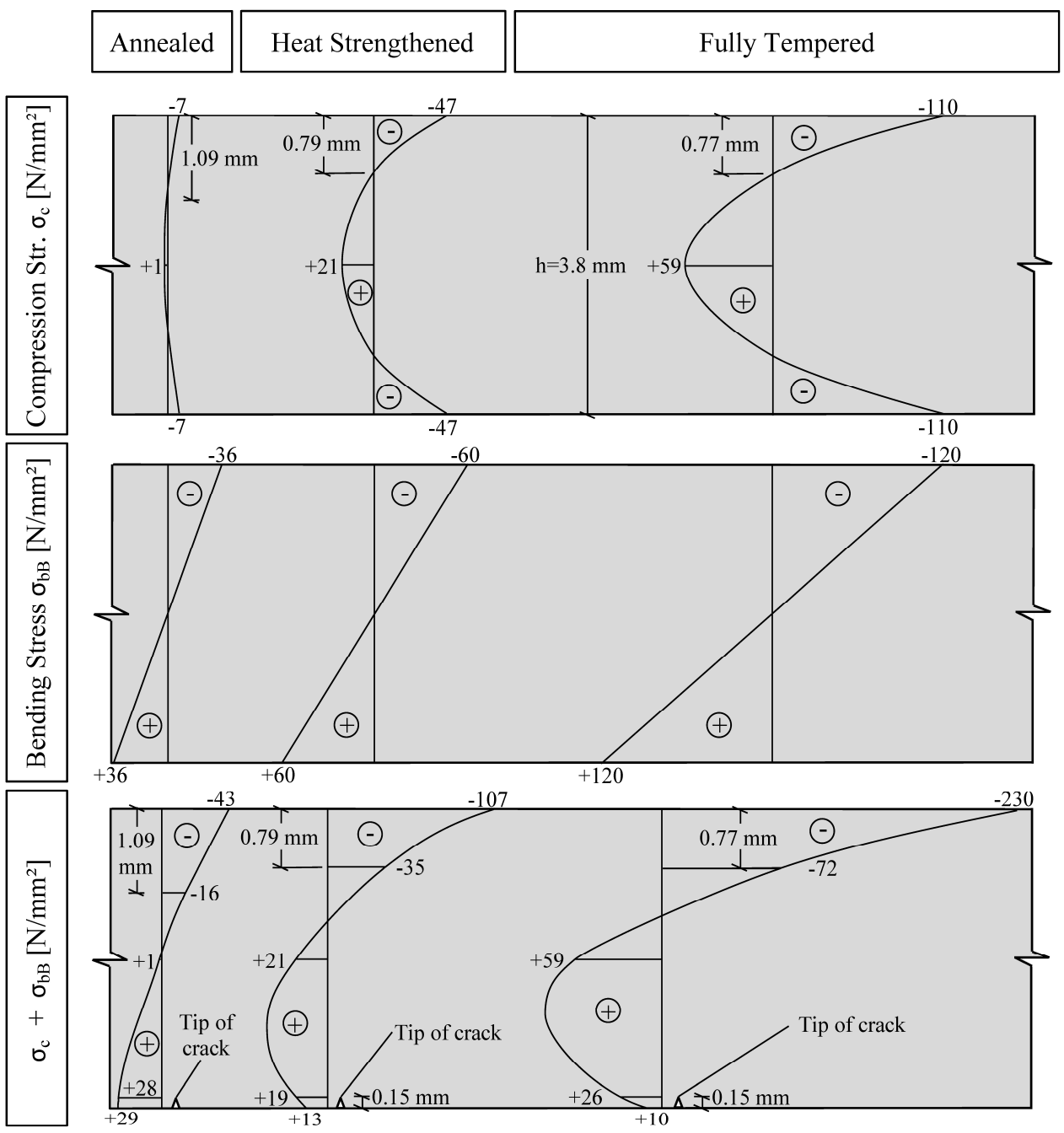

Fig. 8: Typical simplified stress conditions for annealed glass, heat strengthened glass and fully tempered glass: Surface compression stress condition, bending stress condition and their superposition. All values refer to mean values of in total 6 corundum treated test series with 20 specimens per series

\section{Determination of Load Duration Factors $\boldsymbol{k}_{\text {mod }}$ for $\mathrm{HCU}$ Tests}

Equation (8), which is related to inherent stress proportions $\sigma_{i}$, leads to factors $k_{m o d, i B}$ that are related to inherent strength $\sigma_{i B}$. For triangular stress gradient we obtain:

$$
\begin{aligned}
& \int_{0}^{t_{f, L}} \sigma_{i, L}(t)^{n} d t=\int_{0}^{t_{f, H}} \sigma_{i, H}(t)^{n} d t \\
& \int_{0}^{t_{f, L}}\left(\sigma_{i, L} t\right)^{n} d t=\int_{0}^{t_{f, H}}\left(\dot{\sigma}_{i, H} t\right)^{n} d t \\
& \frac{\sigma_{i B, L} \sigma_{i B, L}{ }^{n}}{\sigma_{i, L}(n+1)}=\frac{\sigma_{i B, H} \sigma_{i B, H}{ }^{n}}{\sigma_{i, H}(n+1)} \\
& \frac{\sigma_{i B, L} \sigma_{i B, L}{ }^{n}}{\sigma_{i, L}(n+1)}=\frac{\left(k_{\mathrm{mod}, i B} \sigma_{i B, L}\right)\left(k_{\mathrm{mod}, i B} \sigma_{i B, L}\right)^{n}}{\sigma_{i, H}(n+1)}
\end{aligned}
$$

Using the test conditions $\dot{\sigma}_{i, L}=2 \mathrm{~N} /\left(\mathrm{mm}^{2} \mathrm{~s}\right)$ and $\dot{\sigma}_{i, H}$ $=1,400 \mathrm{~N} /\left(\mathrm{mm}^{2} \mathrm{~s}\right)$, the following solution is valid for positive variables $\sigma_{i B, L}, k_{m o d, i B}$ and $n$ :

$$
k_{\mathrm{mod}, i B}=\left(\frac{1,400}{2}\right)^{\frac{1}{n+1}}=700^{\frac{1}{n+1}}
$$

Finally, factors $k_{\text {mod }}$, related to bending strength $\sigma_{b B}$, can be determined by considering the residual surface compression $\sigma_{c}$ :

$$
k_{\mathrm{mod}}=\frac{\left(k_{\mathrm{mod}, i B} \sigma_{i B, L}\right)-\sigma_{c, H}}{\sigma_{i B, L}-\sigma_{c, L}}
$$


Table 4: Factors $k_{\text {mod }}$ of corundum treated glass determined by risk integral method

\begin{tabular}{|c|c|c|c|c|c|}
\hline $\begin{array}{l}\text { Glass } \\
\text { type } \\
{[-]}\end{array}$ & $\begin{array}{l}\text { Stress rate in center } \\
\text { zone of specimen } \\
\dot{\sigma}\left(\varepsilon_{\mathrm{x}}\right)\left[\mathrm{N} /\left(\mathrm{mm}^{2} \mathrm{~s}\right)\right]\end{array}$ & $\begin{array}{l}\text { Mean value } \mathrm{e}^{\mathrm{a})} \text { of } \\
\text { inherent strength } \\
\sigma_{\mathrm{iB}}\left[\mathrm{N} / \mathrm{mm}^{2}\right]\end{array}$ & $\begin{array}{l}\text { Load duration factor rel. } \\
\text { to inherent strength } \\
\mathrm{k}_{\text {mod,iB }}[-]\end{array}$ & $\begin{array}{l}\text { Mean value }{ }^{\mathrm{a})} \text { of res. } \\
\text { surface compression } \\
\sigma_{c}\left[\mathrm{~N} / \mathrm{mm}^{2}\right]\end{array}$ & $\begin{array}{l}\text { Load duration factor } \\
\mathrm{k}_{\text {mod }}[-]\end{array}$ \\
\hline \multirow[t]{2}{*}{ Annealed } & 2 & 28.7 & 1.41 & -6.9 & 1.33 \\
\hline & 1,400 & - & & -6.6 & \\
\hline \multirow[t]{2}{*}{ Heat strengthened } & 2 & 13.5 & 2.18 & -46.3 & 1.28 \\
\hline & 1,400 & - & & -47.0 & \\
\hline \multirow[t]{2}{*}{ Fully tempered } & 2 & 11.0 & 2.25 & -108.1 & 1.15 \\
\hline & 1,400 & - & & -111.9 & \\
\hline
\end{tabular}

a Based on log-normal distribution

Applying Eq. (11) and (12) for the conducted corundum treated test series leads to the resulting factors $k_{\text {mod }}$ shown in Table 4.

\section{Result Comparison of Mean Value Method with Risk Integral Method for Tests}

The observed maximum deviation of $3 \%$ between factors $k_{\text {mod }}$ of corundum treated glass determined by mean value of bending strength $\sigma_{b B}$ (Table 2) and factors $k_{\text {mod }}$ determined by risk integral method (Table 4 ) is rather small and may not be regarded for structural glass design. As a consequence, the applicability of risk integral method for further investigations in subsequent sections is considered to be verified.

\section{Factors $\boldsymbol{k}_{\text {mod }}$ for Impact and Blast Load at Test Conditions}

After verification of risk integral method for the conducted tests, it is possible to transfer the existing triangular stress gradients into arbitrary stress gradients. For impact and blast load design, the existing triangular stress gradients can be transferred to sinusoidal stress gradients as approximation. Therefore, Eq. (10) can be modified for sinusoidal stress gradients by solving the integral of sine function by series expansion according to Mencik (1992; originally in Evans and Fuller, 1974):

$$
\begin{aligned}
& \int_{0}^{t_{f, L}} \sigma_{i, L}(t)^{n} d t=\int_{0}^{t_{f, \text { Simus }}} \sigma_{i, \text { Sinus }}(t)^{n} d t \\
& \int_{0}^{t_{f, L}}\left(\sigma_{i, L} t\right)^{n} d t=\int_{0}^{t_{f, \text { Sinus }}}\left[\sigma_{i, \text { max }, \text { Sinus }} \sin \left(\frac{\pi}{t_{f, \text { Sinus }}} t\right)\right]^{n} d t \\
& \frac{\sigma_{i B, L} \sigma_{i B, L}^{n}}{\sigma_{i, L}(n+1)}=\frac{\sigma_{i, \text { max }, \text { Sinus }}{ }^{n} t_{f, \text { Sinus }} \sqrt{2 /(\pi n)}}{\left(1+\frac{1}{4 n}+\frac{1}{32 n^{2}}+\ldots\right)} \\
& \frac{\sigma_{i B, L} \sigma_{i B, L}^{n}}{\sigma_{i, L}(n+1)}=\frac{\left(k_{\bmod , i B} \sigma_{i B, L}\right)^{n} t_{f, \text { Sinus }} \sqrt{2 /(\pi n)}}{\left(1+\frac{1}{4 n}+\frac{1}{32 n^{2}}+\ldots\right)}
\end{aligned}
$$

Inserting the low-speed stress rate of $\dot{\sigma}_{i, L}=2$ $\mathrm{N} /\left(\mathrm{mm}^{2} \mathrm{~s}\right)$, the following solution is obtained by solving the equation for $k_{m o d, i B}$ :

$$
k_{\mathrm{mod}, i B}=\frac{1}{\sigma_{i B, L}} E X P\left[\frac{1}{n}\left(-6 \ln (2)+\ln \left(\frac{\sigma_{i B, L}{ }^{n+1}\left(32 n^{2}+8 n+1\right)}{t_{f, \text { Sinus }} \sqrt{2 /(\pi n)} n^{2}(n+1)}\right)\right)\right]
$$

Factors $k_{m o d}$ related to bending strength $\sigma_{b B}$ can be determined by considering the residual surface compression $\sigma_{c}$ :

$k_{\mathrm{mod}}=\frac{\left(k_{\mathrm{mod}, i B} \sigma_{i B, L}\right)-\sigma_{c, L}}{\sigma_{i B, L}-\sigma_{c, L}}$

As the core test specimen series are corundum treated because of the mentioned reasons, the inherent strength $\sigma_{i B, L}$ has to be adjusted according to current standards for structural glass design. The following characteristic bending strength values $f_{k}$ are used for $\sigma_{b B}$ : (1) $45 \mathrm{~N} / \mathrm{mm}^{2}$ for annealed glass (DIN EN 572-1, 2016-06; E DIN EN 16612, 2013-06), (2) $70 \mathrm{~N} / \mathrm{mm}^{2}$ for heat strengthened glass (DIN EN 1863-1, 2012-02; E DIN EN 16612, 2013-06) and (3) $120 \mathrm{~N} / \mathrm{mm}^{2}$ for fully tempered glass (DIN EN 12150-1, 2020-07; E DIN EN 16612, 2013-06). These values represent a 5\% breakage probability with a confidence level of 95\% (DIN 18008-1, 2010-12). For residual surface compression $\sigma_{c}$, the low-speed mean values of Table 4 are used.

For impact and blast load design, load duration factors $k_{\text {mod }}$ are shown below for: (1) annealed glass in Fig. 9, (2) heat strengthened glass in Fig. 10 and (3) fully tempered glass in Fig. 11 for different times until fracture $t_{f}$ and stress histories under HCU testing conditions $\left(20^{\circ} \mathrm{C}\right.$ and $\left.40 \% \mathrm{RH}\right)$. The rise of corundum treated $\sigma_{b B}$ values to current standard characteristic values $f_{k}$ results in a slight increase of factors $k_{\text {mod }}(<3 \%$ for annealed glass, $<14 \%$ for heat strengthened glass and $<1 \%$ for fully tempered glass) for sinusoidal stress history. 


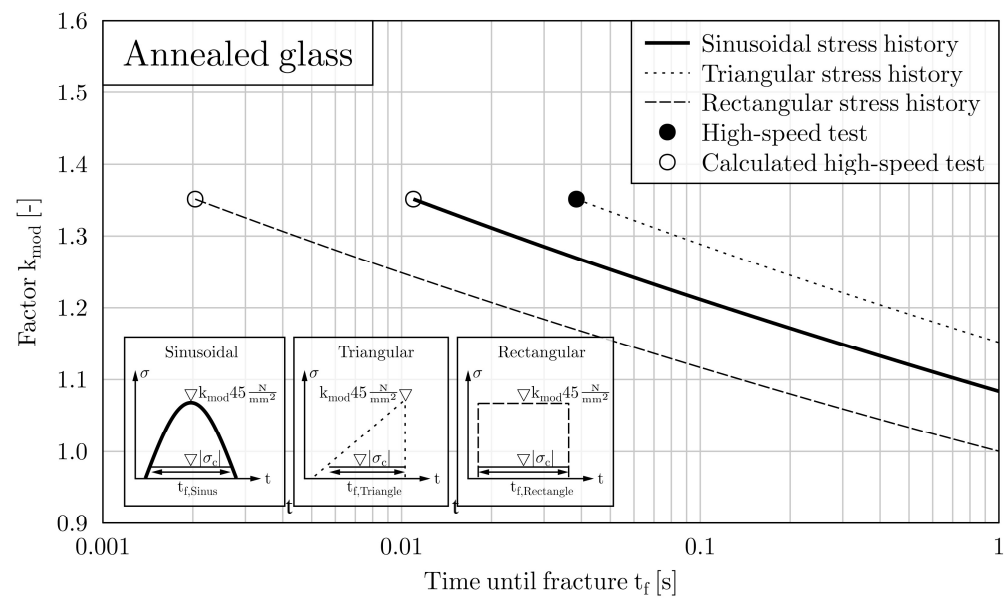

Fig. 9: Factors $k_{\text {mod }}$ for annealed glass under HCU testing conditions $\left(20^{\circ} \mathrm{C}\right.$ and $\left.40 \% \mathrm{RH}\right)$ with characteristic bending strength 45 $\mathrm{N} / \mathrm{mm}^{2}$, representing $5 \%$ breakage probability with a confidence level of $95 \%$

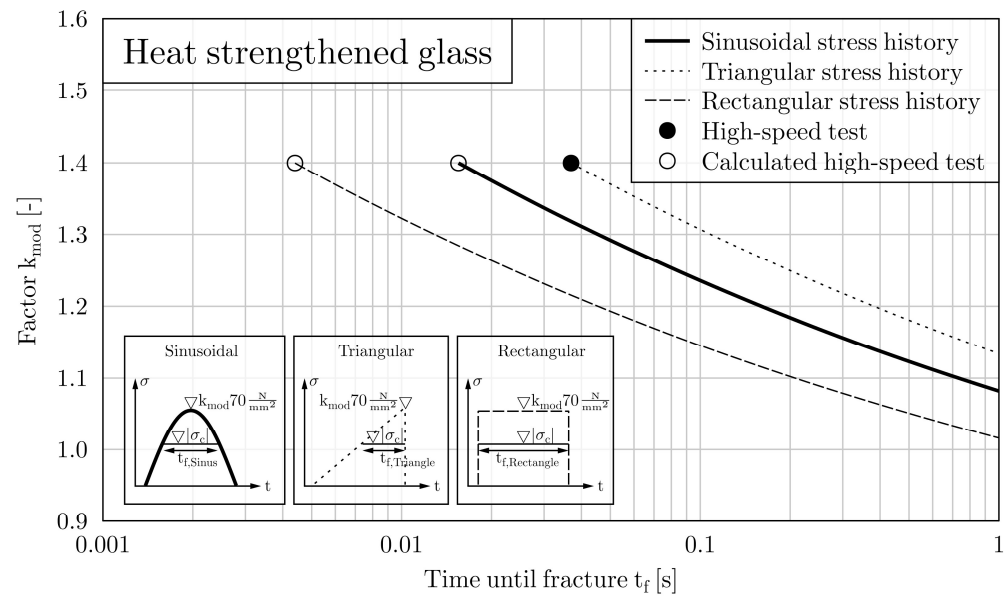

Fig. 10: Factors $k_{\text {mod }}$ for heat strengthened glass under HCU testing conditions $\left(20^{\circ} \mathrm{C}\right.$ and $\left.40 \% \mathrm{RH}\right)$ with characteristic bending strength $70 \mathrm{~N} / \mathrm{mm}^{2}$, representing $5 \%$ breakage probability with a confidence level of $95 \%$

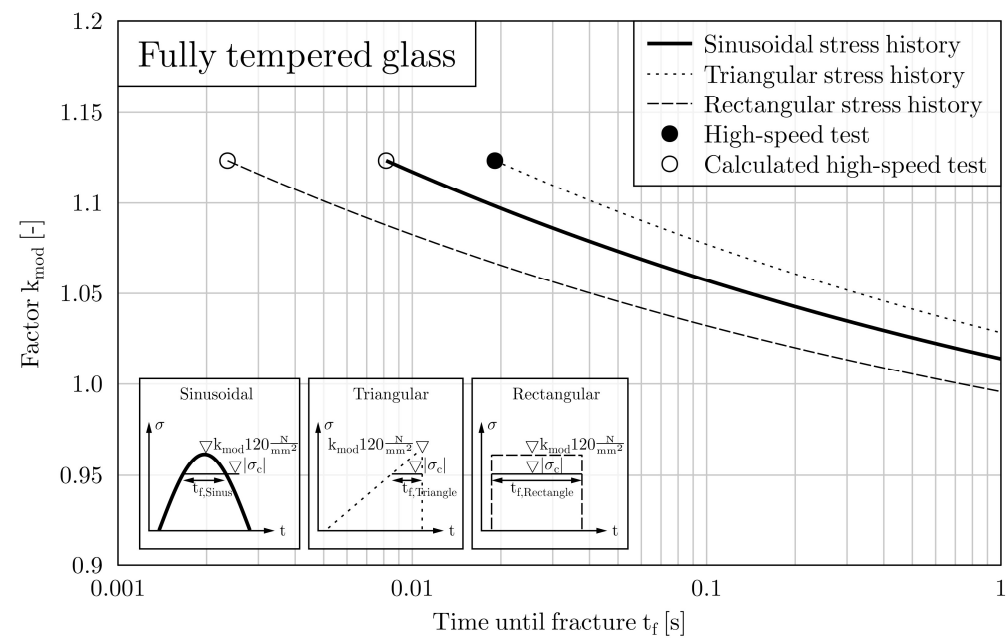

Fig. 11: Factors $k_{m o d}$ for fully tempered glass under HCU testing conditions $\left(20^{\circ} \mathrm{C}\right.$ and $\left.40 \% \mathrm{RH}\right)$ with characteristic bending strength $120 \mathrm{~N} / \mathrm{mm}^{2}$, representing $5 \%$ breakage probability with a confidence level of $95 \%$ 


\section{Proposed Factors $\boldsymbol{k}_{m o d}$ for Impact and Blast Load Design}

The purpose of this Section is to propose factors $k_{m o d}$ for impact and blast load design and compare these factors with European standard E DIN EN 16612 (201306) and German standard DIN 18008-4 (2013-07). However, there are different definitions of factors $k_{\text {mod }}$ in E DIN EN 16612 (2013-06), where factors $k_{\text {mod }}$ are exclusively referenced to the characteristic bending strength of annealed glass (Eq. 1) and DIN 18008-4 (2013-07), where factors $k_{\text {mod }}$ are referenced to the characteristic bending strength of annealed glass, heat strengthened glass or fully tempered glass (Eq. 4). For comparison reasons the definition of DIN 18008-4 (2013-07) according to Eq. (4) is used. For impact and blast load design, the proposed load duration factors $k_{\text {mod }}$ are shown for: Annealed glass in Fig. 12, heat strengthened glass in Fig. 13 and fully tempered glass in Fig. 14. In difference to charts of $k_{\text {mod }}$ of previous Section focusing on differences in stress histories, the present charts compare proposed sinusoidal stress history with regulations of E DIN EN 16612 (2013-06) and DIN 18008-4 (2013-07). In E DIN EN 16612 (201306), there exists no information with regard to the stress history. In contrast, although not explicitly mentioned, there is indication for sinusoidal stress history in DIN 18008-4 (2013-07), e.g., the verification charts for transient calculation (DIN 18008-4, 2013-07). As in Schneider (2001), a duration of impact loads (soft impact) of $40 \mathrm{~ms}$ to $100 \mathrm{~ms}$ is described, the maximum time until fracture $t_{f}$ is limited to $100 \mathrm{~ms}$ for comparison with DIN 18008-4 (2013-07). The minimum load duration according to E DIN EN 16612 (2013-06) is $20 \mathrm{~ms}$. Beside stress history influence, it is important to mention, that the actual factors $k_{\text {mod }}$ of DIN 18008-4 (2013-07) are based on deterministic assumptions, which implement the probability of occurrence of impact loads on the resistance side (Schneider, 2017). This factor may be one reason for the observed difference between factors $k_{\text {mod }}$ presented in DIN 18008-4 (2013-07) and the proposed factors $k_{\text {mod }}$ within this study. However, for structural design of annealed glass, a stress corrosion constant $n=16$ is widely used in Europe and implemented in standards (Blank, 1993; Haldimann et al., 2008; E DIN EN 16612, 2013-06). $n=16$ refers to stress corrosion in water as surrounding medium. While the determination of stress corrosion constant $n$ in water (low value of $n$ ) is on the safe side from short to long term load, it is not for impact and blast load, because here high values of $n$ become relevant (cf. Eq. 14). For that reason, researchers have focused on stress corrosion constants in water as surrounding medium in the past, while only little information related to low relative humidity (high values of $n$ ) exist. In general, relative humidity in blast design can be considered as variable action $\psi_{1,1} Q_{k, 1}(\mathrm{DIN}$ EN 1990, 2010-12):

$$
\begin{aligned}
& E_{d}=\sum_{j \geq 1} G_{k, j} "+" P "+" A_{d} \\
& "+"\left(\psi_{1,1} \text { or } \psi_{2,1}\right) Q_{k, 1} "+" \sum_{i \geq 1} \psi_{2, i} Q_{k, i}
\end{aligned}
$$

$E_{d}$ is the design value of effect of actions, $G_{k, j}$ is characteristic value of permanent action, $P$ is relevant representative value of a prestressing action, $A_{d}$ is design value of accidental action, $Q_{k, i}$ is characteristic value of variable action, $\psi_{1}$ is a frequent value of a variable action and $\psi_{2}$ is a quasi-permanent value of a variable action. Different glass surfaces are usually exposed to different relative humidity values. An insulating glass unit for instance, has glass surfaces exposed to outdoor RH, cavity $\mathrm{RH}$ and indoor RH. In Förch (2019), indoor relative humidity values are investigated for Germany. Based on hourly mean outdoor relative humidity values and hourly mean outdoor air temperature values from 7 weather stations in Germany for a 50 year period, a design value of $13 \%$ $\mathrm{RH}\left(\psi_{1,1} Q_{k, 1}\right)$ for indoor relative humidity is derived (Förch, 2019). Therefore, the indoor RH is design relevant because it is much lower than the outdoor RH. Wiederhorn (1967) investigates stress corrosion constants $n$ in a wide range of $\mathrm{RH}$ (Table 3 ). He identifies the highest value of $n$, in the range between $10 \% \mathrm{RH}$ and water as surrounding medium, at $30 \% \mathrm{RH}$. Although the peak value of $n$ with associated $\mathrm{RH}$ cannot be determined clearly out of this investigation, the testing conditions at $\mathrm{HCU}$ with $40 \% \mathrm{RH}$ are supposed to be in the region of peak value for $n$. Furthermore, cavity $\mathrm{RH}$ values are not design critical when they exceed $10 \%$ RH.

As a result, the following factors $k_{\text {mod }}$ for impact and blast load design with $40 \% \mathrm{RH}$ are proposed for Germany: (1) $k_{\text {mod }}$ for annealed glass in Fig. 12, (2) $k_{\text {mod }}$ for heat strengthened glass in Fig. 13 and (3) $k_{\text {mod }}$ for fully tempered glass in Fig. 14.

Beside the factor $k_{\text {mod }}$, determined under $\mathrm{HCU}$ testing conditions $\left(20^{\circ} \mathrm{C}\right.$ and $\left.40 \% \mathrm{RH}\right)$ with $n=17.9$, two additional curves of factors $k_{\text {mod }}$ for annealed glass under sinusoidal stress history are shown in Fig. 12 for information. Here, only $n$ values are varied for comparison reasons. One curve, representing water as surrounding medium with $n=16$ and the other curve representing $30 \% \mathrm{RH}$ with $n=22.6$ according to Wiederhorn (1967) (Table 3). For heat strengthened glass and fully tempered glass, no stress corrosion constants $n$ have been found in literature. 
Matthias Förch and Frank Wellershoff / International Journal of Structural Glass and Advanced Materials Research 2021, Volume 5: 115.133 DOI: 10.3844/sgamrsp.2021.115.133

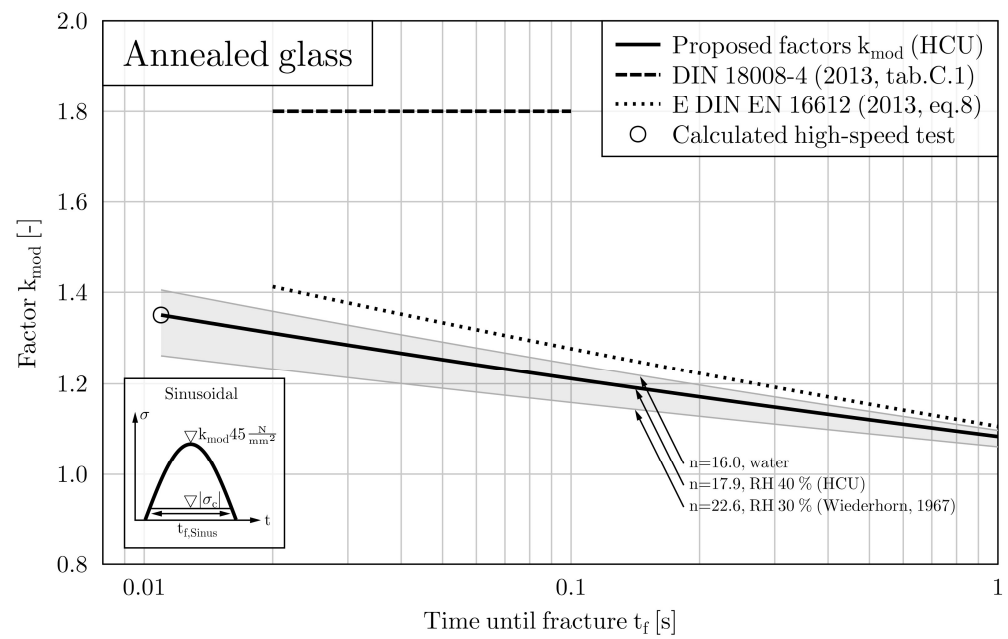

Fig. 12: Proposed factors $k_{m o d}$ for impact and blast load design for annealed glass based on HCU test series with characteristic bending strength $45 \mathrm{~N} / \mathrm{mm}^{2}$, representing $5 \%$ breakage probability with a confidence level of $95 \%$

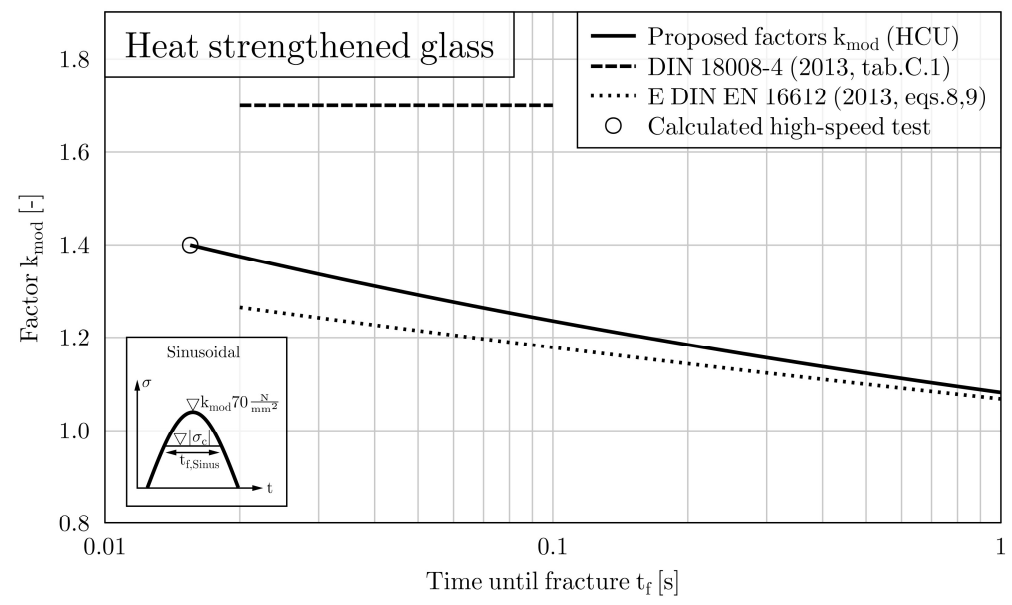

Fig. 13: Proposed factors $k_{m o d}$ for impact and blast load design for heat strengthened glass based on HCU test series with characteristic bending strength $70 \mathrm{~N} / \mathrm{mm}^{2}$, representing $5 \%$ breakage probability with a confidence level of $95 \%$

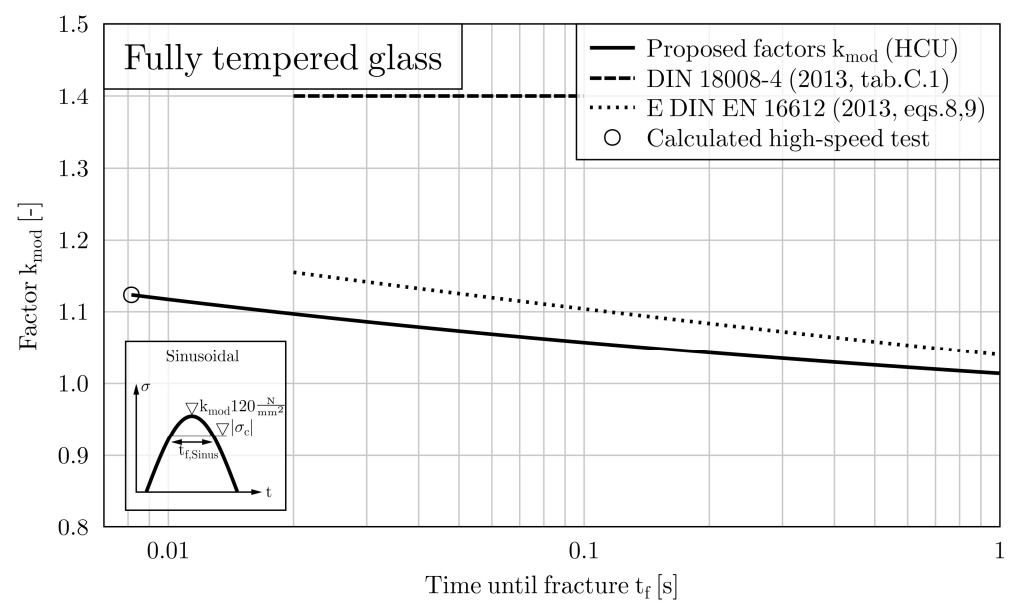

Fig. 14: Proposed factors $k_{m o d}$ for impact and blast load design for fully tempered glass based on HCU test series with characteristic bending strength $120 \mathrm{~N} / \mathrm{mm}^{2}$, representing $5 \%$ breakage probability with a confidence level of $95 \%$ 


\section{Comparison of Test Results at HCU with Other Research}

Glass strength tests under soft impact load are presented for different glass build-ups in Schneider (2001) and monolithic glass in Kuntsche (2015). König (2011) focusses on experimental tension tests of annealed glass specimens under different strain rates with surface condition as delivered. All mentioned research has in common, that no statistically verified evidence is possible due to the limited number of tests. Schula (2015) calculated factors $k_{\text {mod }}$ on theoretical basis for soft impact and stress corrosion constants ranging from $n=14$ to $n=22$ for annealed glass, heat strengthened glass and fully tempered glass based on characteristic bending strength values $f_{k}=45,70$ and $120 \mathrm{~N} / \mathrm{mm}^{2}$, respectively. Table 5 presents an overview of the relevant research data mentioned above.

Meyland et al. (2019) investigate 151 specimens of soda-lime-silica glass at different loading rates with condition as delivered and predamaged. The results of the investigation show significant strength increase for both surface conditions, however, "the number of specimens needs to be increased due to the large scattering to get more profound understanding of the dynamic flexural strength of soda-lime-silica glass" (Meyland et al., 2019). Due to the moderate number of investigated specimens, this research is compared separately to the presented work. Figure 15 shows a comparison of Eq. (12), by utilizing the surface condition as delivered according to Meyland et al. (2019) with $\sigma_{i B, L}=162.1 \mathrm{~N} / \mathrm{mm}^{2}$ and the test results of Meyland et al. (2019) for surface condition as delivered for different levels of stress rate $\dot{\sigma}$.

Here, a clear correlation can be recognized. In addition, Eq. (12) with corundum treated annealed test series of this work $\left(\sigma_{i B, L}=28.7 \mathrm{~N} / \mathrm{mm}^{2}\right)$ for different levels of stress rate $\dot{\sigma}$ is shown for comparison reasons as well as the test result of the present work for corundum treatment. For both equations a surface compression of $\sigma_{c, L}=\sigma_{c, H}=-6.9 \mathrm{~N} / \mathrm{mm}^{2}$ is used.

Figure 16 shows a comparison of Eq. (12), by utilizing the predamaged surface condition according to Meyland et al. (2019) with $\sigma_{i B, L}=49.1 \mathrm{~N} / \mathrm{mm}^{2}$ and the test results of Meyland et al. (2019) for predamaged surface condition for different levels of stress rate $\dot{\sigma}$. Here, a clear correlation can be recognized as well. The difference to Fig. 15 is that the stress rate $\dot{\sigma}$ is decreased to $1 \mathrm{~N} /\left(\mathrm{mm}^{2} \mathrm{~s}\right)$ as no results for $2 \mathrm{~N} /\left(\mathrm{mm}^{2} \mathrm{~s}\right)$ are provided in Meyland et al. (2019). This is the reason, why the term $k_{\text {mod }}$ is modified to $k_{\text {mod }} *$. In addition, Eq. (12) with corundum treated annealed test series of this work $\left(\sigma_{i B, L}=\right.$ $27.9 \mathrm{~N} / \mathrm{mm}^{2}$ ) for different levels of stress rate $\dot{\sigma}$ is shown for comparison reasons. For both equations a surface compression of $\sigma_{c, L}=\sigma_{c, H}=-6.9 \mathrm{~N} / \mathrm{mm}^{2}$ is used.

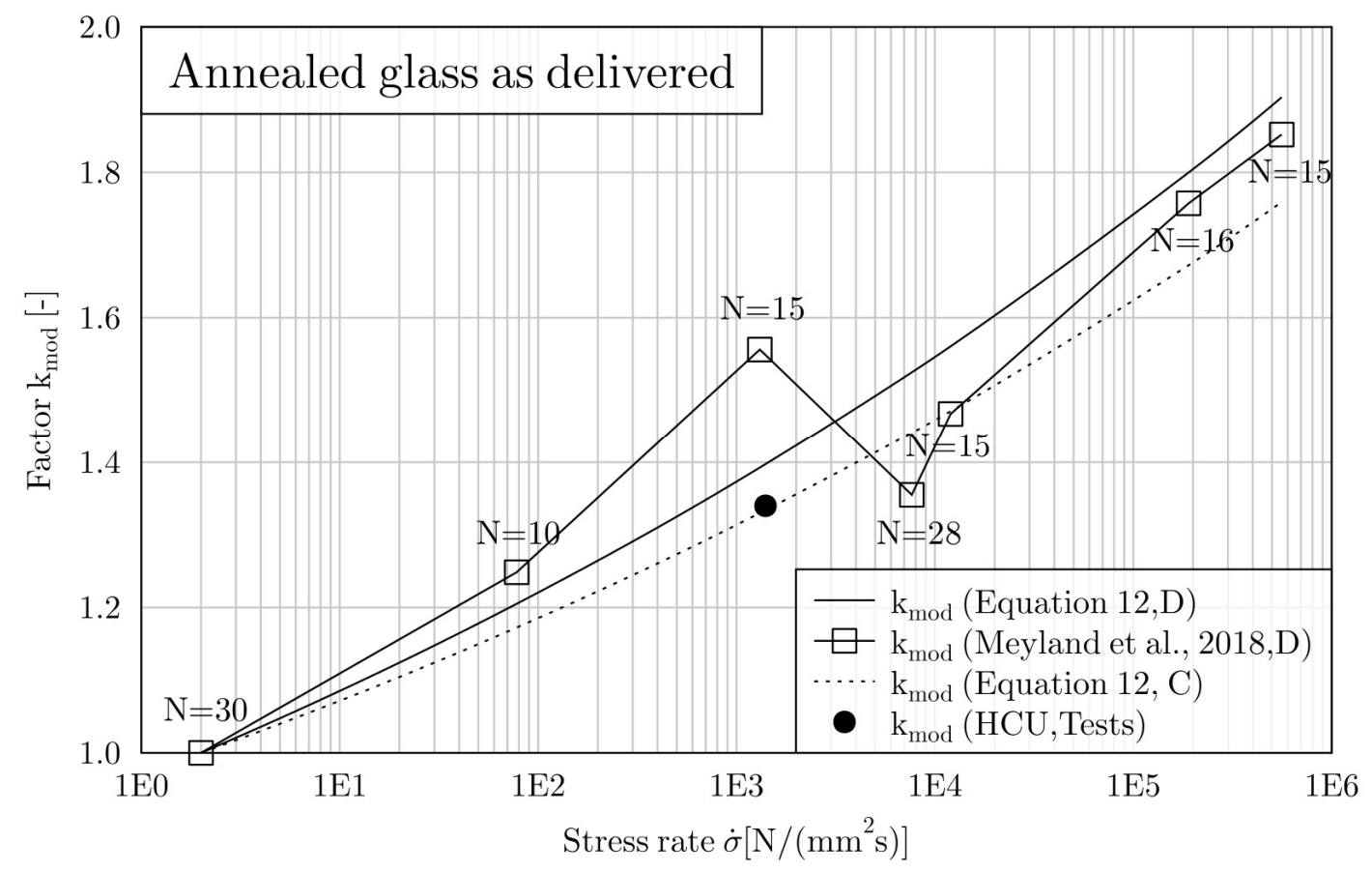

Fig. 15: Comparison of Eq. 12 and the test results of Meyland et al. (2019) for annealed glass with surface condition as delivered (D) and corundum treated $(\mathrm{C})$ 


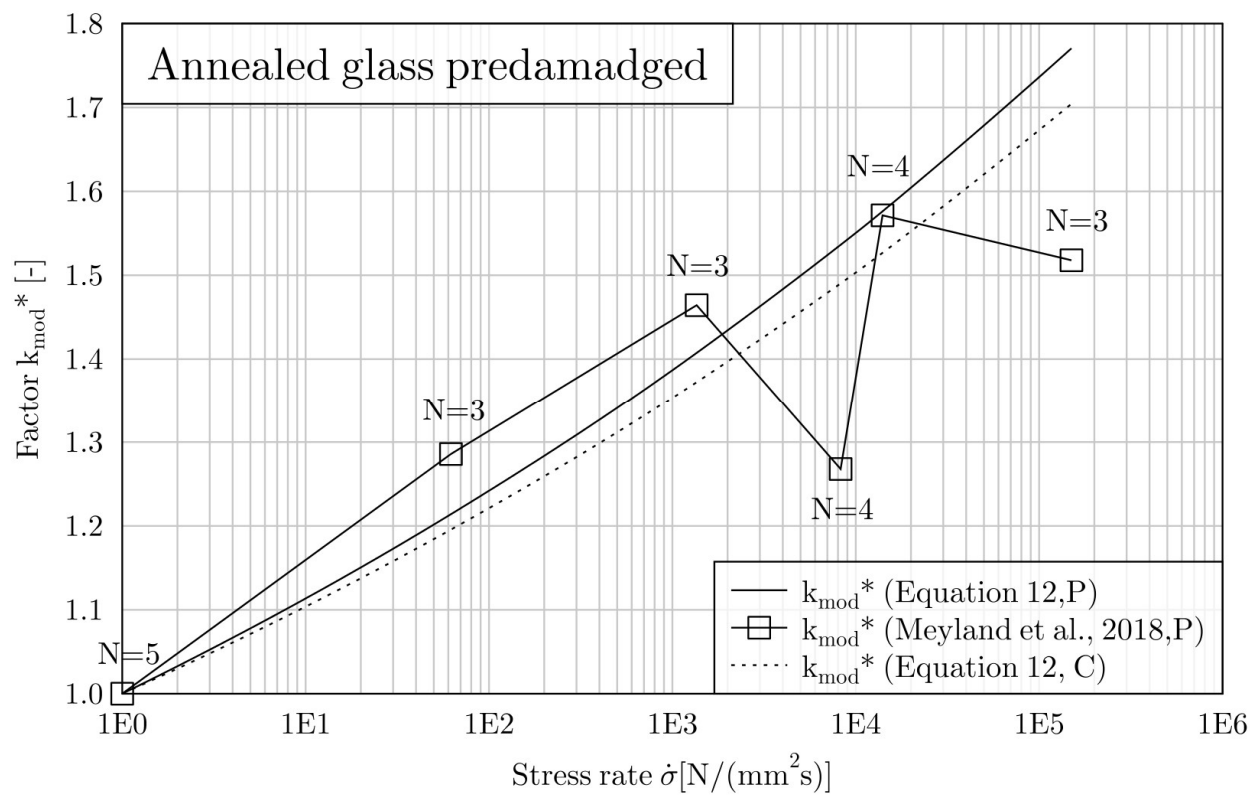

Fig. 16: Comparison of Eq. 12 and the test results of Meyland et al. (2019) for annealed glass with surface condition predamaged (P) and corundum treated $(\mathrm{C})$

Table 5: Comparison of identified factors $k_{m o d}$ with other research

\begin{tabular}{|c|c|c|c|c|c|c|c|}
\hline $\begin{array}{l}\text { Glass type } \\
{[-]}\end{array}$ & $\begin{array}{l}\left.\text { Schneider }(2001)^{\mathrm{a}) \mathrm{b}) \mathrm{d}}\right) \\
{[-]}\end{array}$ & $\begin{array}{l}\left.\text { Kuntsche }(2015)^{\mathrm{a}) \mathrm{b} d \mathrm{~d}}\right) \\
{[-]}\end{array}$ & $\begin{array}{l}\text { Schula }(2015)^{\mathrm{a} e \mathrm{e})} \\
{[-]}\end{array}$ & $\begin{array}{l}\left.\text { König }(2011)^{c) d}\right) \\
{[-]}\end{array}$ & {$[-]$} & $\begin{array}{l}\mathrm{HCU}^{\mathrm{b}) \mathrm{d})} \\
{[-]}\end{array}$ & $\begin{array}{l}\mathrm{HCU}^{\mathrm{b}) \mathrm{f}} \\
{[-]}\end{array}$ \\
\hline Annealed & $1.33-1.56$ & 1.4 & $1.23-1.40$ & $1.28^{\mathrm{g})}$ & $1.20^{\mathrm{h})}$ & $1.25^{\mathrm{i})}$ & $1.34^{\mathrm{i})}$ \\
\hline Heat strengthened & $1.43-1.57$ & 1.8 & $1.15-1.26$ & - & - & - & $1.32^{\mathrm{j})}$ \\
\hline Fully tempered & $1.17-1.25$ & 1.5 & $1.08-1.15$ & - & - & - & $1.15^{\mathrm{j})}$ \\
\hline
\end{tabular}

a Referring to soft impact load

b Bending strength tests

c Tensile strength tests

d Surface condition as delivered

e Calculated values

f Corundum treated surface condition

g Strength increase on mean values between strain rates 9.5 E- $05 \mathrm{~s}^{-1}\left(10\right.$ specimens) and $1 \mathrm{E}-02 \mathrm{~s}^{-1}$ (8 specimens) under triangular stress history

$\mathrm{h}$ Strength increase on mean values between strain rates $9.5 \mathrm{E}-05 \mathrm{~s}^{-1}(10$ specimens $)$ and $5 \mathrm{E}-02 \mathrm{~s}^{-1}$ (8 specimens) under triangular stress history

i Strength increase on mean values (initial crack in mid area) between strain rates 2.9 E-05 $\mathrm{s}^{-1}$ (5 specimens) and 2 E-02 s ${ }^{-1}$ (3 specimens) under triangular stress history

j Strength increase on mean values (initial crack in mid area) between strain rates 2.9 E- $05 \mathrm{~s}^{-1}$ (20 specimens) and 2 E-02 s ${ }^{-1}$ (20 specimens) under triangular stress history (Table 2)

\section{Conclusion}

The presented work contributes to existing knowledge of glass strength under impact and blast loading by proposing load duration factors $k_{\text {mod }}$ up to 1.35 for annealed glass, 1.4 for heat strengthened glass and 1.12 for fully tempered glass. After a general overview of consideration of load duration in standard regulations, the conducted experimental study is presented. Here, 160 specimens were investigated in four point bending tests under low-speed and high-speed conditions, while most of the specimens were treated with corundum P16 to reduce the variation of bending strength and guide the initial crack in the mid area of the specimen. As a result, the present study provides high statistical evidence. However, test results from annealed glass specimens with surface conditions as delivered and higher variation are in the same range as for annealed glass with corundum treatment. Further to a verification of risk integral method for the conducted tests, load duration factors are determined for sinusoidal stress gradients applicable for glass panel 
response under impact and blast load for test conditions. Furthermore, load duration factors $k_{\text {mod }}$ for annealed glass, heat strengthened glass and fully tempered glass under impact and blast loading are proposed on the basis of Eurocode concept and stress corrosion conditions such as relative humidity. Finally, a comparison with other research and standards shows good correlation to the references E DIN EN 16612 (2013-06) and Meyland et al. (2019). On the basis of the present results and mentioned research sufficient data are available to adapt load duration factors for impact and blast design in standards.

\section{Acknowledgement}

The authors would like to acknowledge the laboratory staff Dipl.-Ing. (FH) Jens Ohlendieck, Dipl.-Ing. (FH) Marcus Illguth, M. Eng. and Jens Eidenberg as well as student assistants Marta Karczewska and Pakdad Pourbozorgi Langroudi, M.Sc., who ably assisted in preparation and execution of all experiments reported.

\section{Author's Contributions}

Matthias Förch: Conception and design of study, experimental testing, analysis and interpretation of data and writing the manuscript.

Frank Wellershoff: Design of research plan and data analysis as well as interpretation of data.

\section{Ethics}

The content of this study is part of the doctoral dissertation Förch (2019) at HafenCity University Hamburg (HCU), where further information is given. The authors would like to thank the association for structural glass "FKGFachverband Konstruktiver Glasbau e.V." for the financial support and permission to publish research results with regard to the project "Glass Strength at High Strain Rates". All glass specimens were sponsored by Glas Trösch, member of FKG. The authors confirm that there is no conflict of interest and that the funding sources had no involvement in form and content of the research.

\section{References}

Ahlers, E. B. (1969). Fragment hazard study. ITT RESEARCH INST LANHAM MD.

ASTM E1300-16 (2016). Standard practice for determining load resistance of glass in buildings. West Conshohocken, Pa. https://www.astm.org/Standards/E1300.htm

ASTM F2248-12 (2012). Standard practice for specifying an equivalent 3 -second duration design loading for blast resistant glazing fabricated with laminated glass.
Blank, K. (1993). Dickenbemessung von vierseitig gelagerten rechteckigen Glasscheiben unter gleichförmiger Flächenlast-Forschungsbericht, Heft 3 der Veröffentlichungsreihe des Institutes für konstruktiven Glasbau IKG. 2. Aufl. Gelsenkirchen.

Brown, W. G. (1969). A load duration theory for glass design. Division of Building Research, National Research Council.

Cormie, D., Mays, G., \& Smith, P. (2009). Blast effects on buildings: design of buildings to optimize resistance to blast loading.

DIN 18008-1 (2010-12) Glass in building. Design and construction rules. Part 1: Terms and general bases, Beuth, Berlin.

DIN 18008-4 (2013-07) Glass in building. Design and construction rules. Part 4: Additional requirements for barrier glazing. Beuth, Berlin. https://www.beuth.de/en/standard/din-180084/181278792

DIN EN 12150-1 (2020-07) Glass in building. Thermally toughened soda lime silicate safety glass. Part 1: Definition and description. German version EN 12150-1:2015.

Beuth, Berlin.https://standards.globalspec.com/std/1431505 9/DIN\%20EN\%2012150-1

DIN EN 1288-3 (2000-09) Glass in building. Determination of the bending strength of glass. Part 3: Test with specimen supported at two points (four point bending). German version EN 1288-3:2000. Beuth, Berlin. https:/global.ihs.com/doc_detail.cfm?document_name $=\mathrm{DIN} \% 20 \mathrm{EN} \% 201288 \% 2 \mathrm{D} 3 \&$ item_s_key $=00365608$

DIN EN 1863-1 (2012-02) Glass In Building-Heat Strengthened Soda Lime Silicate Glass-Part 1: Definition And Description; German Version 18631:2011. Beuth, Berlin. https://webstore.ansi.org/standards/din/dinen18632012

DIN EN 1990 (2010-12) Eurocode: Basis of structural design. German version EN 1990:2002 + A1:2005+A1:2005/AC:2010. Beuth, Berlin. https://standards.globalspec.com/std/1304839/dinen-1990

DIN EN 572-1 (2016-06) Glass in building. Basic soda-lime silicate glass products. Part 1: Definitions and general physical and mechanical properties. German version EN 572-1:2012+A1:2016. Beuth, Berlin. https:/global.ihs.com/doc_detail.cfm?document_name $=\mathrm{DIN} \% 20 \mathrm{EN} \% 20572 \% 2 \mathrm{D} 1 \&$ item_s_key $=00229442$

E DIN EN 16612 (2013-06) Glass in building. Determination of the load resistance of glass panes by calculation and testing. German version prEN 16612:2013. Beuth, Berlin. https://www.beuth.de/de/norm-entwurf/din-en$16612 / 186538843$ 
Elsayed, N. M., \& Atkins, J. L. (2008). Explosion and Blast-Related Injuries. Elsevier Academic Press, London.

Evans, A. G., \& Fuller, E. R. (1974). Crack propagation in ceramic materials under cyclic loading conditions. Metallurgical transactions, 5(1), 27-33.

Förch, M. (2019). Analysis of Glass Panels Subjected to Blast Load (Vol. 1). Springer.

Gehrke, E., \& Ullner, C. (1988). Makroskopisches Rißwachstum, Inertfestigkeit und Ermüdungsverhalten silikatischer Gläser.

Gehrke, E., Ullner, C., \& Hähnert, M. (1987). Correlation between multistage crack growth and time-dependent strength in commercial silicate glasses. I: Influence of ambient media and types of initial cracks. Glastechnische Berichte, 60, 268-278.

Güsgen, J. (1998). Bemessung tragender Bauteile aus Glas. Shaker.

Glazing Hazard Guide. (1997). Glazing Hazard Guide (Restricted) Security Facilities Executive Services Group-Explosion Protection. Cabinet Office, London.

Haldimann, M., Luible, A., \& Overend, M. (2008). Structural use of glass (Vol. 10). Iabse.

Harpole, T. (1995). A safety lesson from oklahoma-city. Progressive Architecture, 76(6), 65-66.

Kerkhof, F., Richter, H., \& Stahn, D. (1981) Festigkeit von Glas - Zur Abhängigkeit von Belastungsdauer und verlauf. In: Glastechnische Berichte, 54, 8: 265-277.

König, C. (2011). Dehnratenabhängigkeit mechanischer Werkstoffkennwerte von Kalk-Natronsilicatglas (Doctoral dissertation).

Kuntsche, J. K. (2015). Mechanical behavior of laminated glass under time-dependent and explosion loading (Vol. 46). Springer publishing house.

Lawn, B. (1993). Fracture of brittle solids. Cambridge University press.

Marsh, D. M. (1964). Plastic flow and fracture of glass. Proceedings of the Royal Society of London. Series A. Mathematical and Physical Sciences, 282(1388), 33-43.

Mencik, J. (1992). Strength and fracture of glass and ceramics. North-Holland.

Meyland, M. J., Bønding, C. K., Eriksen, R. N., \& Nielsen, J. H. (2019). An experimental investigation of the flexural strength of soda-limesilica glass at high loading rates. Glass Structures \& Engineering, 4(2), 175-183.

Mould, R. E., \& Southwick, R. D. (1959). Strength and static fatigue of abraded glass under controlled ambient conditions: II, Effect of various abrasions and the universal fatigue curve. Journal of the American Ceramic Society, 42(12), 582-592.
Nie, X., Chen, W. W., \& Templeton, D. W. (2010). Dynamic ring-on-ring equibiaxial flexural strength of borosilicate glass. International Journal of Applied Ceramic Technology, 7(5), 616-624.

Peroni, M., Solomos, G., Pizzinato, V., \& Larcher, M. (2011). Experimental investigation of high strainrate behaviour of glass. In Applied Mechanics and Materials (Vol. 82, pp. 63-68). Trans Tech Publications Ltd.

Richter, H. (1974). Experimentelle Untersuchungen zur Rißausbreitung in Spiegelglas im Geschwindigkeitsbereich $10^{\wedge}-3$ bis $5 \times 10^{\wedge} \mathrm{mm} / \mathrm{s}$. Freiburg, Inst. f. Festkörpermechanik. Wiss. Ber. Nr.9.

Schneider, J. (2017). Email correspondence with Univ.Prof. Dr.-Ing. Jens Schneider (Darmstadt University of Technology) on July, 4th 2017

Schneider, J. (2001). Festigkeit und Bemessung punktgelagerter Gläser und stoßbeanspruchter Gläser. Inst. für Statik.

Schneider, J., Kuntsche, J., Schula, S., Schneider, F., \& Wörner, JD (2016). Glass construction: basics, calculation, construction. Springer publishing house. https://www.springer.com/de/book/9783540284765

Schula, S. (2015). Charakterisierung der Kratzanfälligkeit von Gläsern im Bauwesen: Characterisation of the scratch sensitivity of glasses in civil engineering (Vol. 43). Springer-Verlag.

Sedlacek, G., Blank, K., Laufs, W., \& Güsgen, J. (1999). Glas im konstruktiven Ingenieurbau. Ernst \& Sohn

Sglavo, V. M., \& Green, D. J. (1995). Influence of indentation crack configuration on strength and fatigue behaviour of soda-lime silicate glass. Acta metallurgica et materialia, 43(3), 965-972.

Siebert, G. (2001). "Entwurf und Bemessung von tragenden Bauteilen aus Glas". Published by Ernst \& Sohn Verlag für Architektur und technische Wissenschaften $\mathrm{GmbH}$, Berlin.

Smith, P. D., \& Hetherington, J. G. (1994). Blast and ballistic loading of structures. Butterworth-Heinemann.

UFC 3-340-02 (2008). Structures to resist the effects of accidental explosions. Unified Facilities Criteria (UFC). US Department of Defense. https://www.wbdg.org/ffc/dod/unified-facilitiescriteria-ufc/ufc-3-340-02

Ullner, C., \& Höhne, L. (1993). Untersuchungen zum Festigkeitsverhalten und zur Rissalterung von Glas unter dem Einfluss korrosiver Umgebungsbedingungen. Technial report, Bundesanstalt für Materialforschung und-prüfung (BAM) in cooperation with Fraunhofer-Institut für Werkstoffmechanik, Berlin.

Weigel, G. (1980). Wirkungen des Luftstoßes von nuklearen und konventionellen Explosionen. Zivilschutzforschung Bd. 10. 
Matthias Förch and Frank Wellershoff/ International Journal of Structural Glass and Advanced Materials Research 2021, Volume 5: 115.133 DOI: 10.3844 /sgamrsp.2021.115.133

Wiederhorn, S. M. (1967). Influence of water vapor on crack propagation in soda-lime glass. Journal of the American Ceramic Society, 50(8), 407-414.
Wiederhorn, S. M., \& Townsend, P. R. (1970). Crack healing in glass. Journal of the American Ceramic Society, 53(9), 486-489. 